
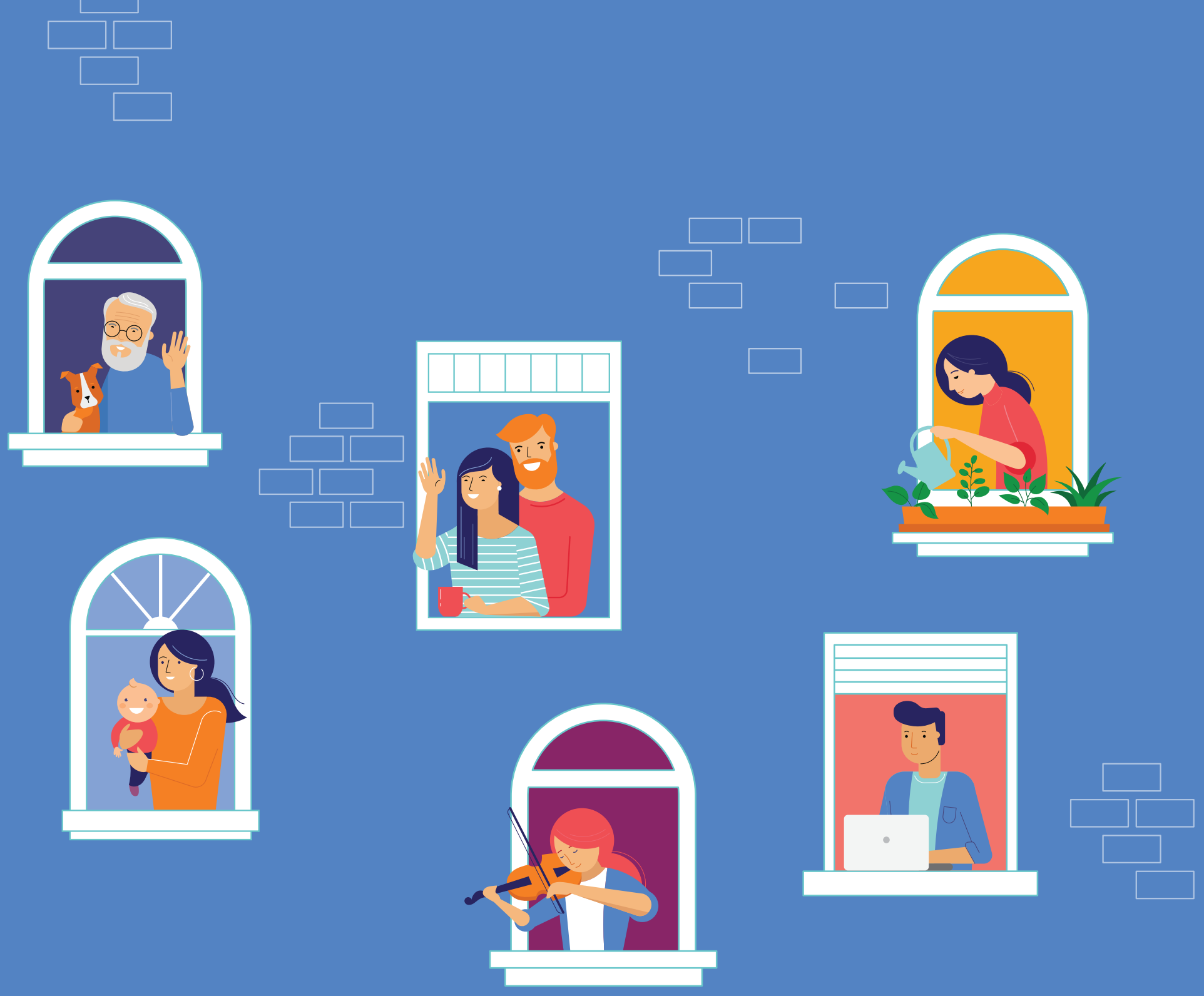

\title{
Coping During Covid-19
}

\section{Workbook}

A CBT approach to coping with COVID-19

related anxiety \& depression

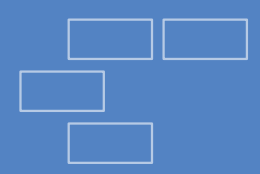

Dr. Keith Gaynor

Saint John of God Hospital

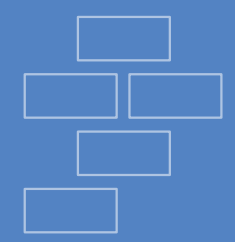




\section{Acknowledgements}

2020 was a year where solidarity and community spirit were on show everywhere we looked. I would like to mention just three examples here. I want to thank Eamon Aswad for his exceptional hard work in helping put together this workbook. I am very grateful for the community spirit of all the staff of Saint John of God Hospital throughout this time. Finally, I would like to acknowledge the courage and creativity of all the people with anxiety and depression during this pandemic. People endured the unendurable, and developed new ways of living and seeing the world. The people that I met, most often through Zoom, were an extraordinary inspiration. 



\section{Introduction \\ to Coping During COVID-19}

\section{What is this workbook?}

2020 saw the world affected by an unprecedented pandemic. Alongside the health risks, COVID-19 has created mental health difficulties for a large number of people. Many people are feeling anxious or depressed, in ways that they might never have before. There are many causes but we suggest that there are four critical reasons why people might feel low or anxious at this time:

(i) The significant health risk.

(ii) The isolation and disconnection from friends, family and supports.

(iii) The economic threat to many people's livelihoods.

(iv) The diminishment of our identities.

In the middle of this international health emergency, it is clear the risks are real and very serious. If we haven't been affected medically, then probably we have been affected economically or socially. It is natural for us to feel frightened or low.

We all have ways of coping during stressful times. Unfortunately, COVID-19 has robbed us of access to many of our supports and ways of coping.

This eight module workbook is designed to support those who are struggling with symptoms of anxiety and depression because of the COVID-19 crisis. This workbook has been created to give you some tools to help. It doesn't replace formal psychological or medical support but may be an additional resource.

\section{What is CBT?}

This workbook uses Cognitive Behavioural Therapy (CBT). Over the last 30 years, CBT has been shown to be an approach that is helpful in reducing anxiety and depression.

We present a specific model of how anxiety and depression related to COVID-19 works. Each module is designed to tackle one component of this model.

The cognitive part (the ' $C$ ' part of CBT), looks at the thoughts and beliefs people have in anxiety provoking or depressing situations. The behavioural part (the 'B' part of CBT) looks at what people do when they're feeling anxious or low. 
As you can imagine, two people might think about a situation in different ways ( $\mathrm{C}$ - cognitive), and this will have a big impact on how they feel about it and what they do ( $B$ - Behavioural) when faced with that situation. The two have a direct reciprocal effect on each other. If I have depressed thoughts, I'm likely to have behaviours that reinforce those thoughts.

CBT includes strategies designed to help individuals identify and challenge negative thoughts or interpretations that are maintaining anxiety.

The goal of CBT is not to "think happy thoughts" or "be positive"; instead, the goal is to shift negative thinking so that it becomes more balanced. It is also to help us to notice when we get lost in negative or unhelpful thinking and gently move us out of this thinking pattern. CBT includes strategies to change unhelpful behaviours.
This workbook includes a variety of behavioural strategies, including; relaxation, gradual exposure to feared situations, muscle relaxation exercises, reducing unhelpful behaviours that contribute to anxiety (e.g. avoidance), and testing out our beliefs using experiments.

All of these strategies acknowledge the real risks that exist. In a COVID world, we have to be safe and we don't suggest any behavior that might put you at risk of contracting COVID-19.

\section{How to use this workbook}

It is recommended that this workbook can be completed by anyone who is over the age of eighteen and is willing to engage with tackling anxiety and depression that may have arrived or increased a result of the COVID-19 crisis.

(continued next page)

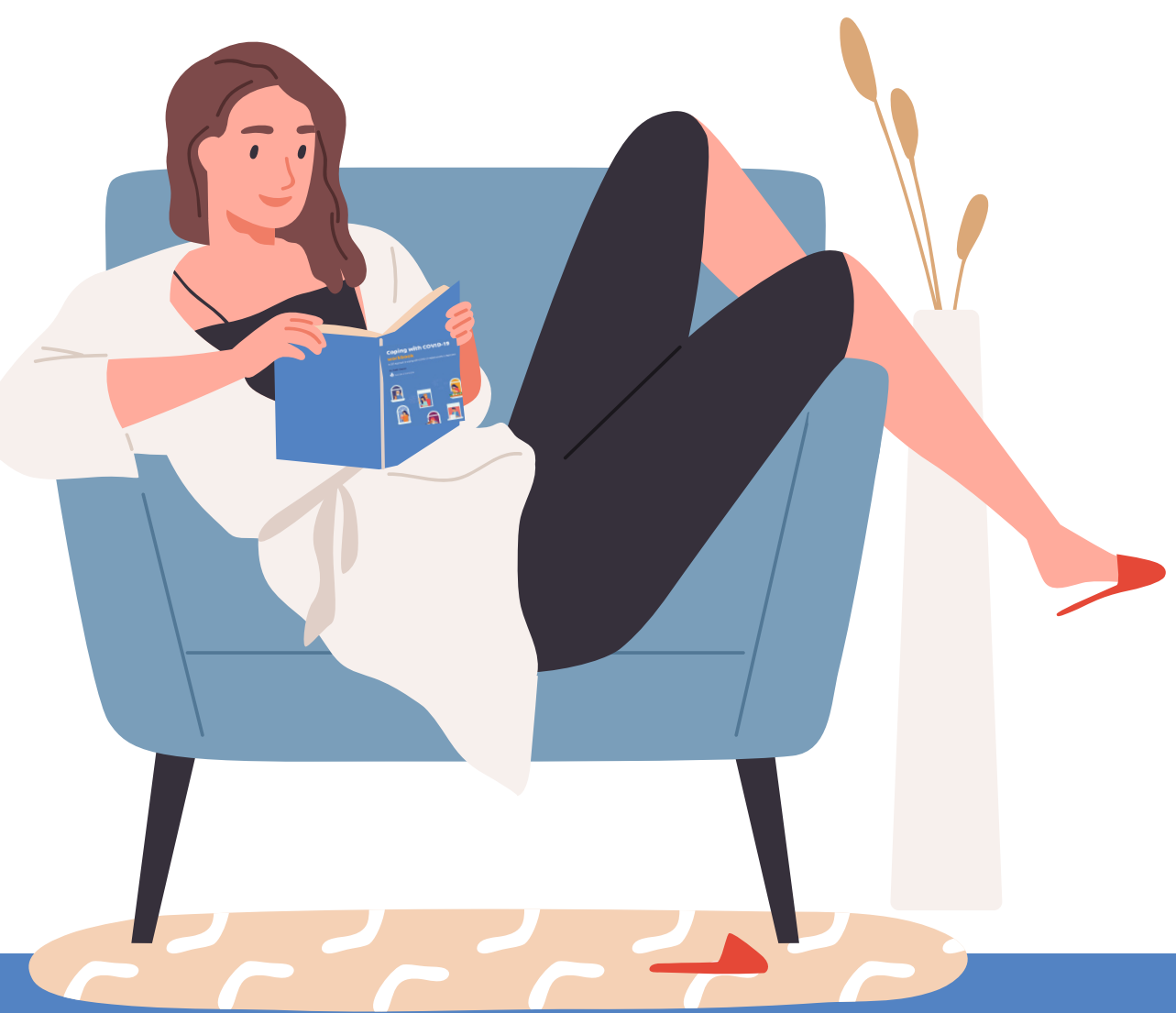




\section{Key Message}

\section{8}

It is important to understand that anxiety or low mood is something you do, NOT who you are.

In the English language, we say "I am anxious".

In the Irish language, we say "Tá imníoch orm". The anxiety is on me.

It is not who I am, it is something which is on me for the moment and will pass.

Through this workbook, we hope to help people maintain a positive quality of life, despite all the challenges in the world.

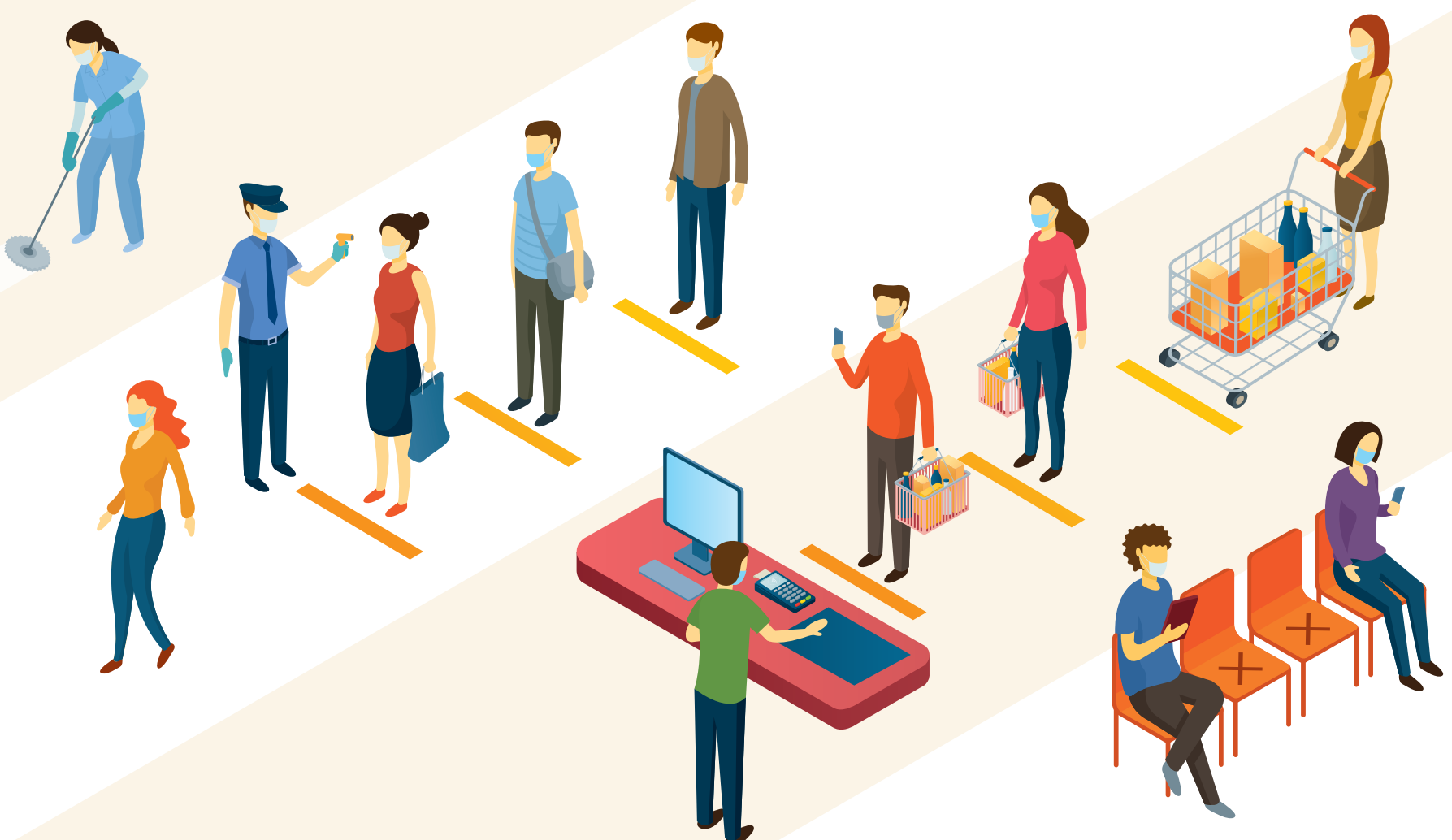




\section{Module 1:}

\section{The Psychological Impact of the COVID-19 Crisis}

Coronavirus will be imprinted on the personality of our nation for a very long time" - Dr Anthony Fauci

\section{Module Aims:}

1. To raise awareness of $C B T$ and Biopsychosocial models of anxiety and depression.

2. To learn about your own anxiety/low mood and their triggers.

3. To reflect on the impact the COVID-19 crisis has had on you.

\section{What values are important to you?}

Please take a moment to write down some of the values which are important to you.

Staying in touch with these values, despite the pandemic, is the goal of this course.

1.

2.

3.

4.

5.

Now, what steps may you need to take in order to keep these values alive during the pandemic? 


\section{How COVID-19 can affect us: The Biopsychosocial Model}

The Biopsychosocial model describes how biological, psychological and social factors interact. For instance, I might be socially isolated and feel lonely and this might affect my sleep. Or I might feel a racing heart, feel panicky, and stop going to the shops or other public places. These factors don't operate on their own but in a cycle. If we can make one positive change, it will have a positive impact on all the other areas.

\section{Diagram 1.}

The biological has an impact on the psychological and on the social and vice versa. Please take a moment to examine the Biopsychosocial model. This incorporates biological, psychological and social factors.

\section{Example: Biopsychosocial Impact}

Please take a look at Diagram 2 overleaf. This is an example of how the biopsychosocial model displays the impact of the COVID-19 crisis. In the biological you can see the components that disrupt your biology. In the psychological the factors that cause stress or worry. In the social it contains factors that cause possible interpersonal or social issues.

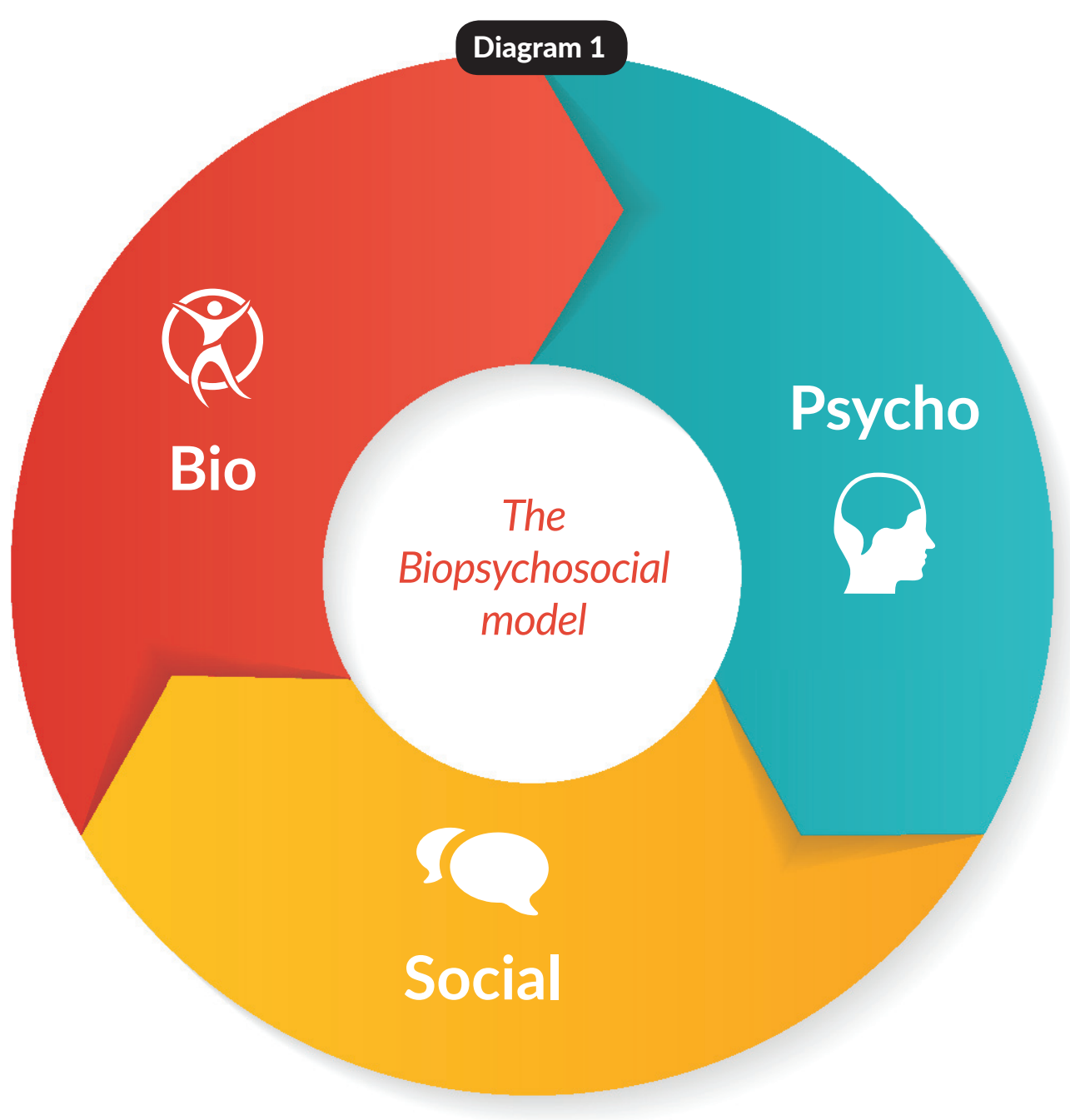




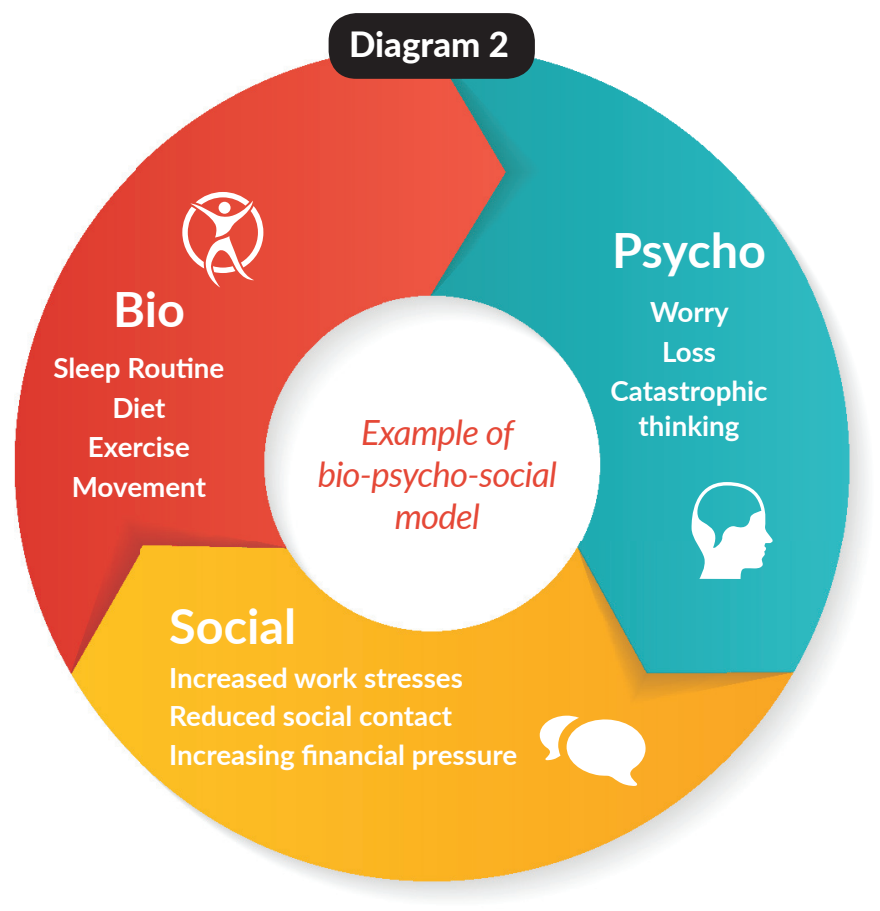

\section{Complete a Personal Biopsychosocial Model}

Think about the biological, psychological and social factors that may be impacting you during the COVID-19 crisis. Then complete the personal biopsychosocial model below (Diagram 3).

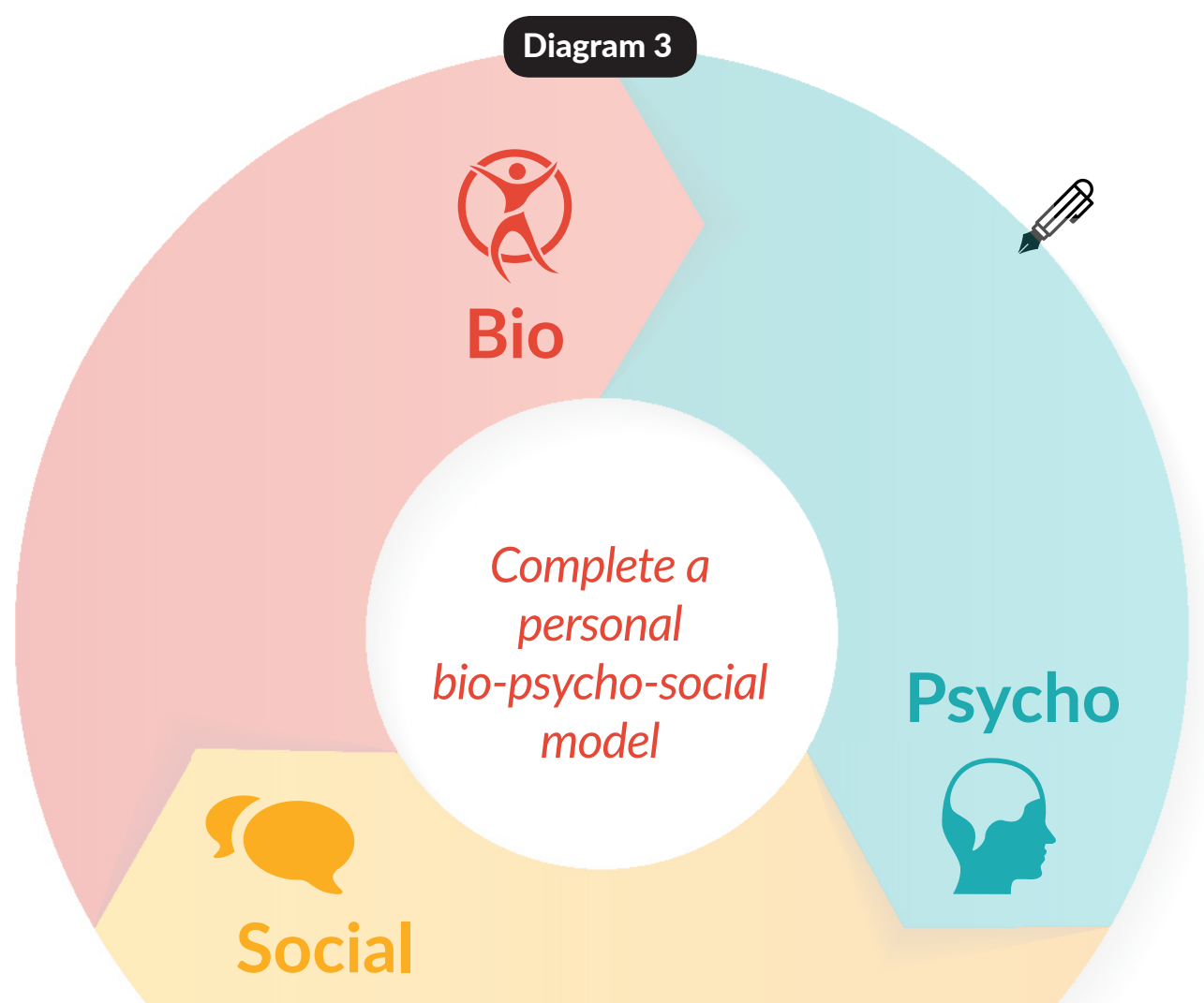




\section{CBT Model of Anxiety and Depression}

Researchers have identified three clear causes of anxiety and depression during the pandemic: the impact of isolation, risk to our health and the financial and family impact. I would like to add another cause: the impact on our identity. When we can't do our normal things or see our normal friends and family, it has a significant impact on us. Not being able to play five-a-side on a Wednesday or attend an amateur dramatic society might not seem like much but when it is an integral part of our identity then we feel a great sense of loss when it's not there.

\section{Diagram 4}

A CBT model of COVID-19 anxiety and depression

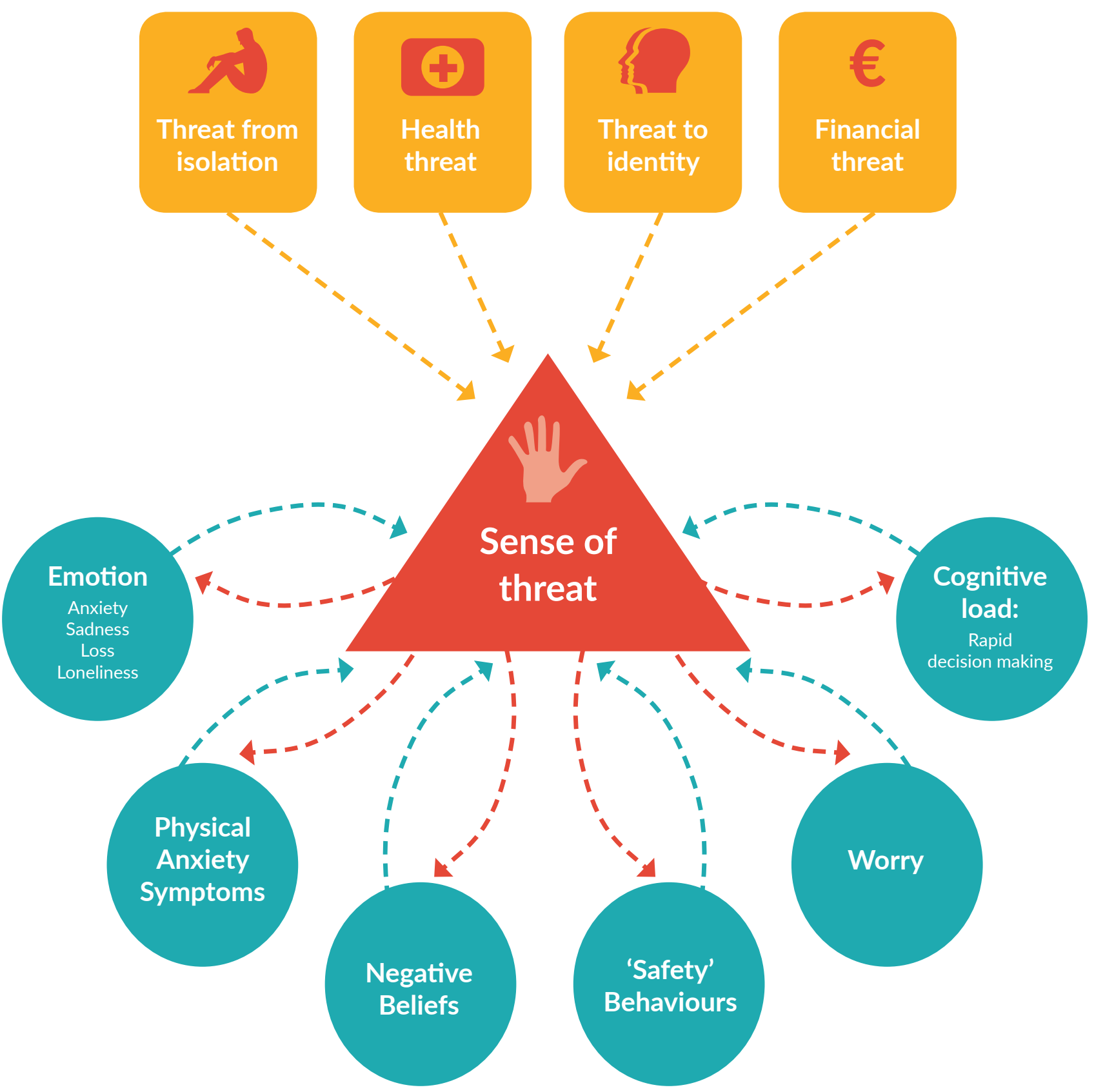




\section{A CBT Model of COVID-19 Anxiety and Depression}

As you can see from the CBT model of anxiety and depression, the key theme is a sense of threat. This sense of threat may come from many different avenues: isolation, health, financial/practical or identity.

$\mathrm{CBT}$ teaches us that how we react to this sense of threat can make it better or worse. We often can't control the things that threaten us but we can control how we react to them. In this workbook we are going to work through the 6 reactions that can increase the sense of threat.

Anxiety occurs in response to perceived threats.

In humans it can also be triggered by the threat of loss. These questions might be helpful to understand your own triggers to COVID-19.

These reactions are: emotional, physical, negative thinking, behaviour, worry, and cognitive load. We will to try to give you

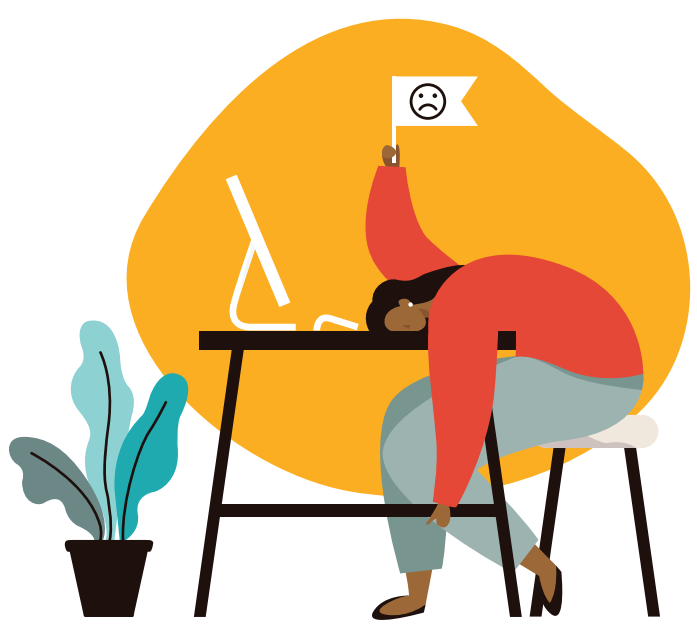
the resources to manage your own reactions.

In order to understand the best way to manage your own anxiety, it is important to understand your own triggers. A trigger can range from a sight, smell or situation that sets off your thoughts, behaviours feelings or emotions.

\section{Please write down your triggers to the questions below.}

When do I become anxious or low?

Why do I think I become anxious or low?

Do I have any external triggers? (e.g. news, conversations, lack of activity)

Do I have any bodily sensations that act as a trigger?

Do I have any thoughts that act as a trigger? 


\section{A CBT Model of COVID-19 Anxiety and Depression (cont'd)}

What aspect of COVID-19 do you find threatening?

Has it caused/or has it the potential to cause a loss in your life?

\section{Practice Task - Diary}

In order to use the information from this module, over the course of the next week, keep a diary of when the following things occur (please complete the diary on the following page).

1. Triggers (What trigger? When? Why?)

2. How does my body feel?

3. Any thoughts or beliefs about COVID-19?

4. Is my sense of self/identity challenged?

5. How often do I worry?

6. What do I worry about?

7. When do I feel lonely or isolated?

8. Do I do anything unnecessary to keep myself safe?

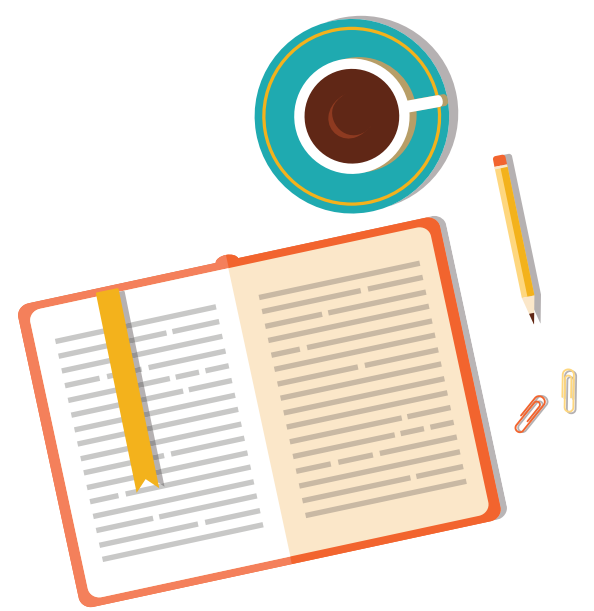

\section{Module Summary: Learning Points}

1. The COVID-19 crisis has created a sense of threat and resulted in many losses in our lives.

2. We can understand the impact of these through the Biopsychosocial model or the CBT model.

3. If we can make one change, it will have a positive impact on other aspects of the models. 
Diagram 6

Diary of features of anxiety and depression

\begin{tabular}{|c|c|c|c|c|c|c|c|}
\hline & Monday & Tuesday & Wednesday & Thursday & Friday & Saturday & Sunday \\
\hline $\begin{array}{l}\text { Triggers } \\
\text { What trigger? } \\
\text { When? Why? }\end{array}$ & & & & & & & \\
\hline $\begin{array}{l}\text { How does } \\
\text { my body } \\
\text { feel? }\end{array}$ & & & & & & & \\
\hline $\begin{array}{l}\text { Thoughts } \\
\text { Thoughts or } \\
\text { beliefs about } \\
\text { COVID-19 }\end{array}$ & & & & & & & \\
\hline $\begin{array}{l}\text { Identity } \\
\text { Is my sense of } \\
\text { self/identity } \\
\text { challenged? }\end{array}$ & & & & & & & \\
\hline $\begin{array}{l}\text { How often } \\
\text { do I worry? }\end{array}$ & & & & & & & \\
\hline $\begin{array}{c}\text { What do I } \\
\text { worry } \\
\text { about? }\end{array}$ & & & & & & & \\
\hline $\begin{array}{l}\text { When do I } \\
\text { feel lonely or } \\
\text { isolated? }\end{array}$ & & & & & & & \\
\hline $\begin{array}{c}\text { Do I do } \\
\text { anything } \\
\text { unnecessary } \\
\text { to keep } \\
\text { myself safe? }\end{array}$ & & & & & & & \\
\hline
\end{tabular}




\section{Notes}

Use this space for any extra notes or thoughts you have on your progress through the Workbook so far.

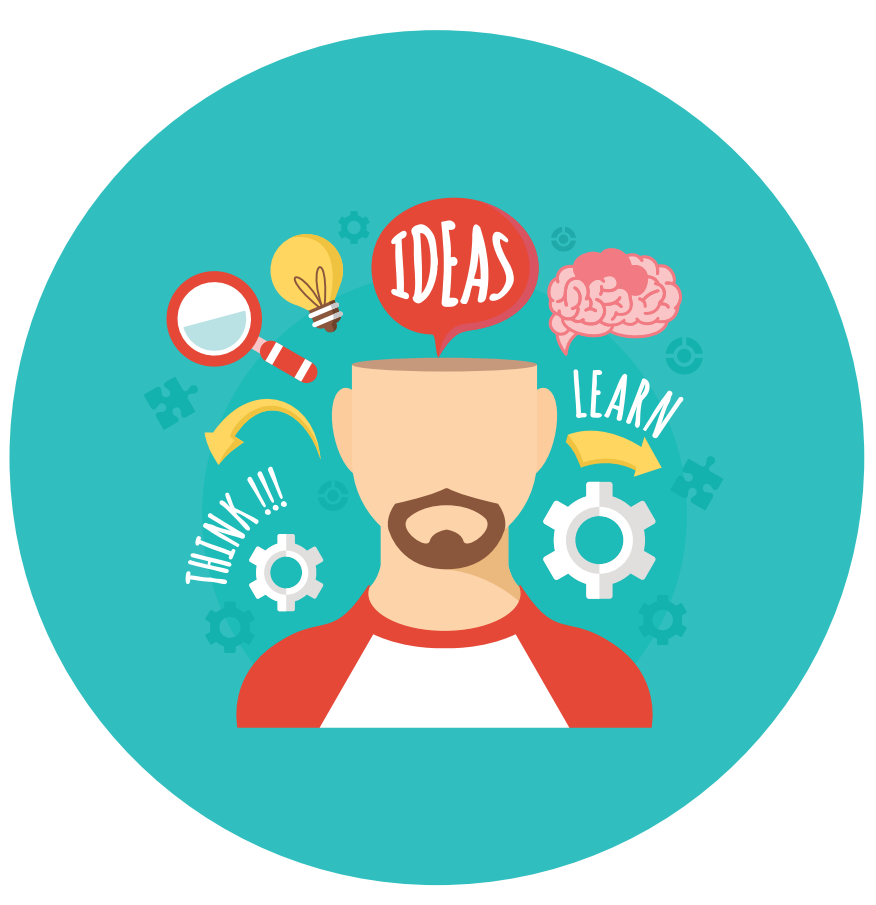




\section{Module 2:}

How Our Bodies Respond to Anxiety

Sometimes the most important thing in a whole day is the rest taken between two deep breaths" - Etty Hillesum

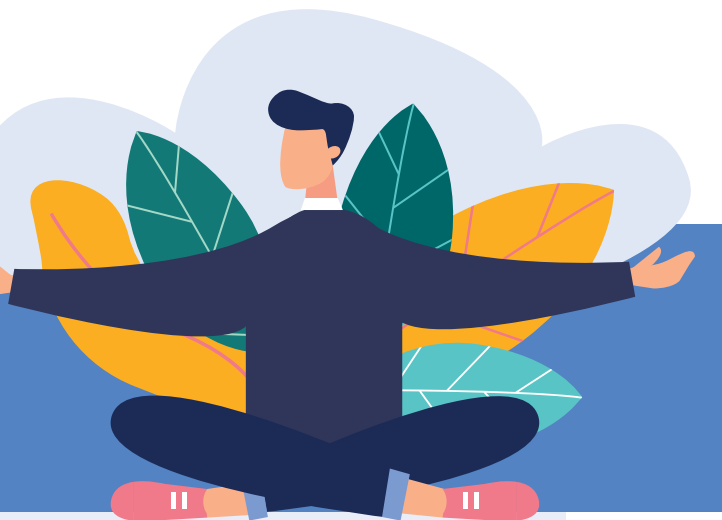

\section{Module Aims:}

1. Gain an understanding of the Fight or Flight response of anxiety.

2. Start using strategies for tolerating physical anxiety, such as: body-orientated coping strategies, grounding, breathing and body scan exercises.

3. Practice, Practice, Practice!

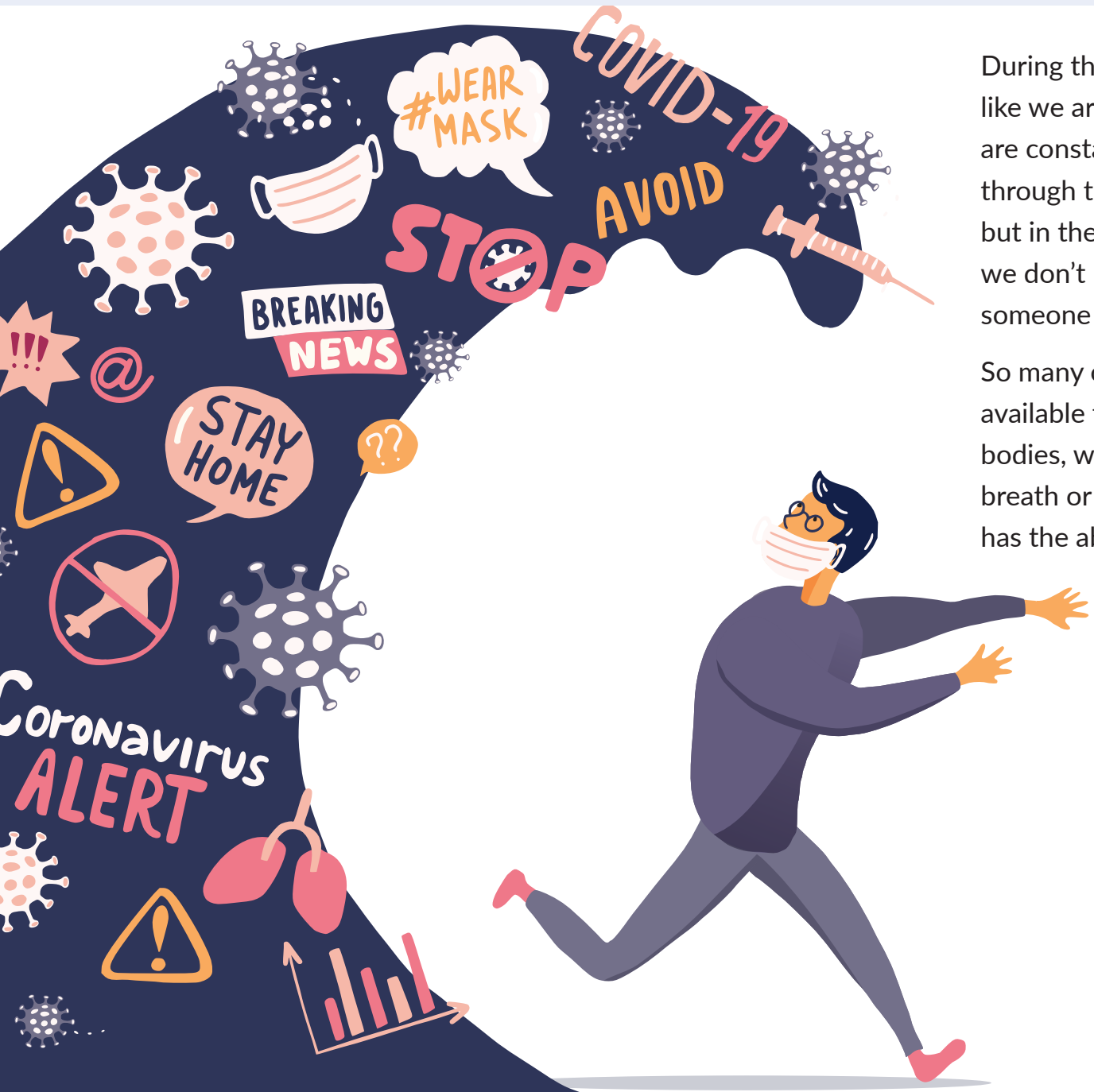




\section{Fight, Flight or Surrender}

What is happening in our body when we have anxiety? Our heart rate increases. Our breathing speeds up. The blood is pushed to our hands, feet and sometimes our cheeks (this is why we blush when we are embarrassed). This is called the Fight or Flight response. There are a few good things to know:

- It cannot harm you.

- If you are faced with a perceived threat, it triggers our body's natural anxiety response system.

- It's designed to protect us, not harm us.

- It was very important to stone-age humans. If you faced a ferocious animal, you must fight or run! It's the system we require to evade threat e.g. if a bus is about to run us over, it helps us quickly jump out of the way!

Sometimes it can feel like this natural reaction can last forever. This is also because of how intense fight and flight is. But it won't last forever. In fact, unless we do something to prolong it, typically, it only lasts for about 1 hour.

The fight or flight response naturally comes down over time.

\section{Diagram 7}

Fight and Flight Response

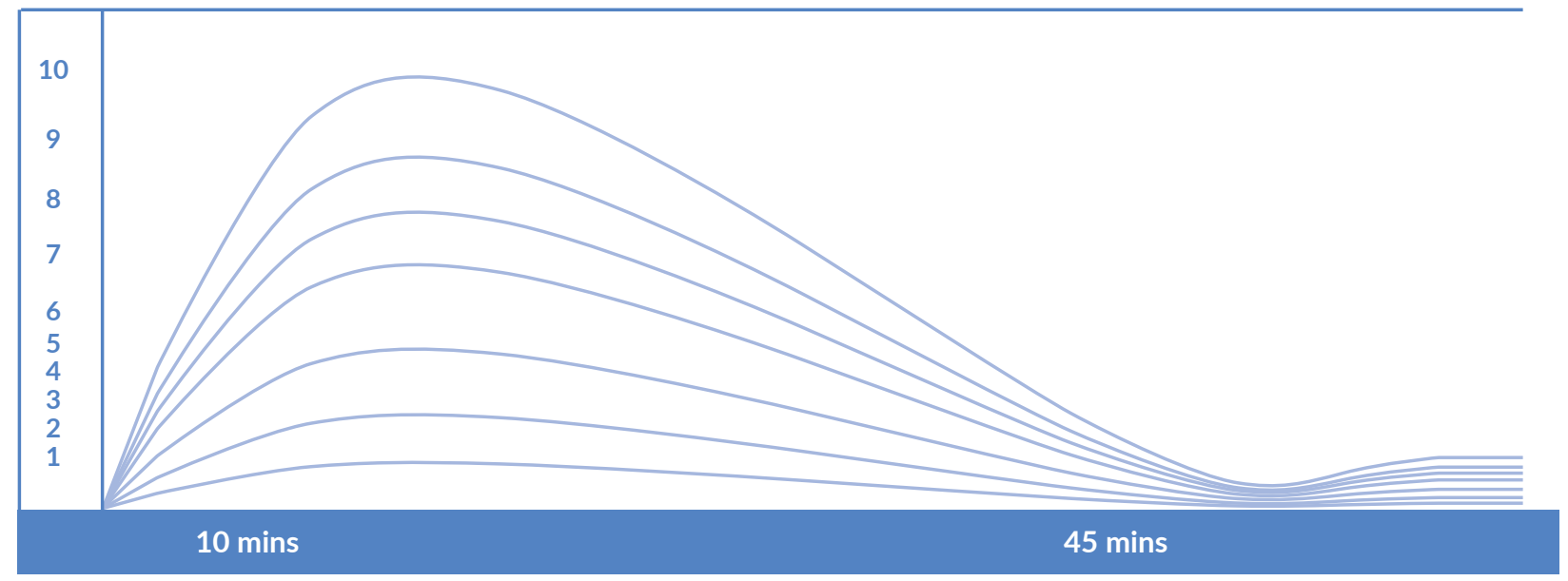

\section{What helps to tolerate anxiety?}

The fight and flight response wants to go down. If we can tolerate anxiety, the fight and flight response will gradually go down itself. The strength and duration of the anxiety will reduce the more we get accustomed to it. Here are some things it is helpful to know:

Know that the anxiety has a time course and it will end.

We must move away from worrying thoughts and get into the practical.

Accept that 'this is what it is', for the moment.

$\checkmark$ Engage with where we are and be present in the moment. 


\section{Coping strategies}

Another way to deal with anxiety is by using coping strategies. Remember there are many different forms of coping strategies or resources. Resources can be: Psychological, Relational, Somatic (in the body), Emotional, Intellectual, Artistic/Creative, Spiritual, Nature, Material.

Unfortunately, Covid-19 may have robbed us of access to many of these resources, however, but not access to our own bodies. Body-oriented coping strategies are resources that you already have, so you can use them to help you in managing anxiety.

The following are four body oriented coping strategies that I find helpful.

\section{Breathing Exercise}

The following exercise just asks you to breathe normally and to notice, not to change your breath. Close your eyes and start to notice your breath coming in and your breathing coming out. Allow this to continue for five minutes or so.

\section{Grounding Exercise 1}

The following exercise is a grounding exercise. 'Grounding' is a technique that allows you to cope with your anxiety, by grounding or reconnecting you with the earth.

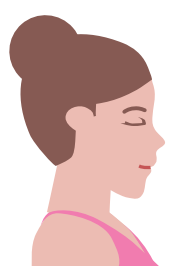

Read the instructions down below and acknowledge the sensations and feelings of your body. Gently ask yourself some of the questions included and explore how you feel.

Whenever you feel the need you can always come back and use these exercises or maybe even get to the point where you may be able to learn and memorise the steps.

- Sitting in your chair, first take a moment to feel the floor under your feet.

- Then gently push your feet into the ground, against the floor.

- Experiment with finding just the right amount of pressure so it feels good. Notice the difference with more or less pressure. Play with the amount of pressure or with stomping your feet against the ground.
- What happens physically? What happens to your heart rate? Do you feel more present or less present in your body? Is it easier or harder to breathe? What happens to your posture?

\section{Grounding Exercise 2}

(The same as Grounding Exercise 1 but standing up)

Stand with your feet on the floor.

- Paying attention to how your whole body feels when you make a point of firmly grounding your feet to the floor.

- What then happens to you physically? Do you feel more or less present in your body?

- Is it easier or harder to breathe? What happens to your posture?

\section{(Moving your body)}

- What happens if you sit and collapse your head and shoulders?

- What happens to your breath? How easy is it to turn your head left and right?

-What happens if you then lengthen your posture, as if you wanted to tower over someone or even intimidate someone? What happens to your breath? Your posture? Your mood?

- Lastly, what happens if you try and sit normally? Allow your body to find its natural stance, and then very slowly lengthen your spine (from the bottom of your back up to your shoulders). 


\section{Body Scan Exercise}

This next exercise is an example of a body scan exercise. You can use it to increase day-to-day awareness.

- When sitting or lying quietly, just close your eyes or let your eyes lose focus slightly.

- Then pay attention to your body. Starting from the tip of your head, working slowly downwards through your head, your neck, shoulders, arms, chest, stomach, buttocks, legs, feet.

- Pay attention and notice where where you may feel more or less tension.

- Then what would it be like to gently breathe into the space that you feel the tension.

- See what it's like to gently move the area where you feel the tension.

- Place one hand on your heart, and one hand on your belly.

- Slowly bring your awareness to what that feels like.

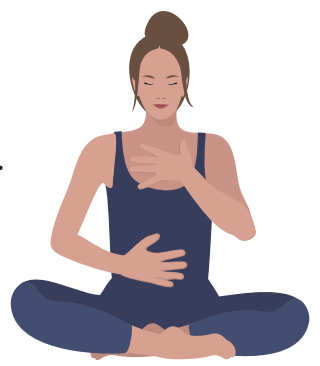

- Notice the feeling of your hands. The weight of your hands. The warmth or coolness of your hands.

- Notice the feeling of your breath meeting your hands. Notice what happens inside when you focus all of your attention on your two hands.

Remember, using these techniques appropriately often takes some time and practice. If you feel that you are getting frustrated or one does not suit you, focus on using the exercises that you feel you get the most benefit from. (For example, if you prefer breathing exercises to grounding exercises.)

The great thing about these exercises is that the only resource that is required is your time. Whenever you feel the need to use them to help manage your anxiety or have some free time, try to incorporate one or more into your daily routine.

\section{Practice Task - Diary}

Use the space below to jot down some learning points from Module 2: How Our Bodies Respond to Anxiety.

Practice one of the body exercises: grounding, breathing or body scan each day

Keep a note or diary of how you found the practice.

\section{Module Summary: Learning Points}

1. Anxiety is our body's natural response to threat.

2. Anxiety naturally wants to come down.

3. We can use body-focused techniques to help our bodies relax. 


\section{Module 3:}

Worry and Rumination

You don't have to control your thoughts. You just

have to stop letting them control you." - Dan Millman

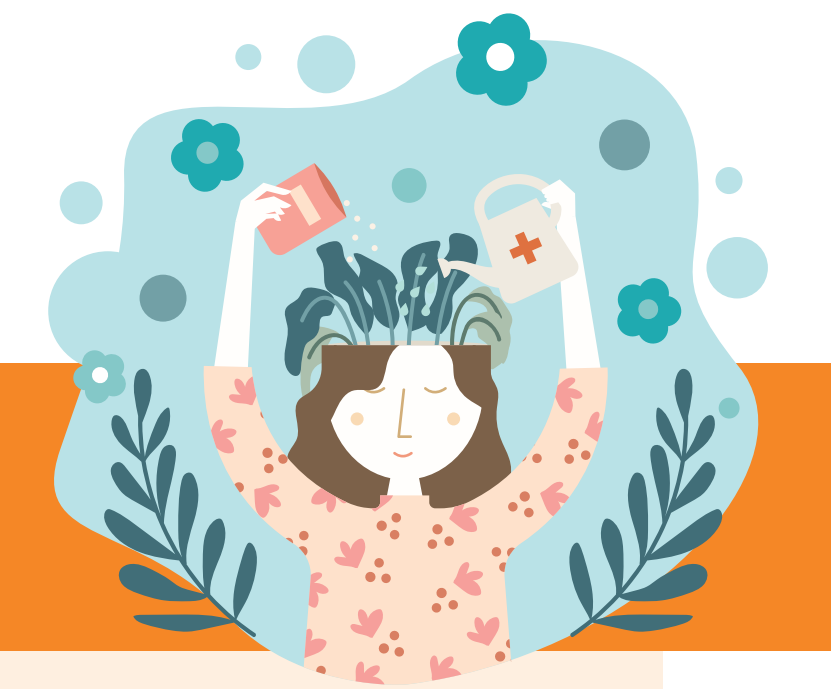

\section{Module Aims:}

1. Understand and learn about the circular nature of worry; how worry motivates us to take action but how inaction can be debilitating.

2. Implement the $\mathbf{8}$ steps to reduce worry and the associated behaviours (checking, seeking reassurance, procrastination, distraction and avoidance).

\section{Worry}

We all know what worry is... but it is difficult for us to exactly put our finger on it.

Here are some aspects of worry:

- It is mental - our minds think of something stressful.

- It is emotional - we feel unpleasant anxiety.

- It is physical - we feel it in our bodies.

- It is repetitive - it repeats and repeats and repeats...

However, worry has a function:

- It is problem solving for a future problem. Worry must have been really very useful for our ancestors. People in the Stone Age were probably great worriers!

- Even the awful feeling of anxiety has a function. This common function is that it pushes or motivates us to do something to remove that terrible feeling.

\section{So, what is the issue with worrying?}

- Pre-empting future problems and doing something about them is a good idea.

- However, worry without action is not a good idea... it just leaves us worried.

- Worry can make us agitated.

- Worry can push us into over-checking and reassurance seeking.

- We get so worried that we don't even want to think about the problem (avoidance).

- We end up in an ever-escalating cycle of worry and avoidance. 


\section{Diagram 8}

Worry is Circular

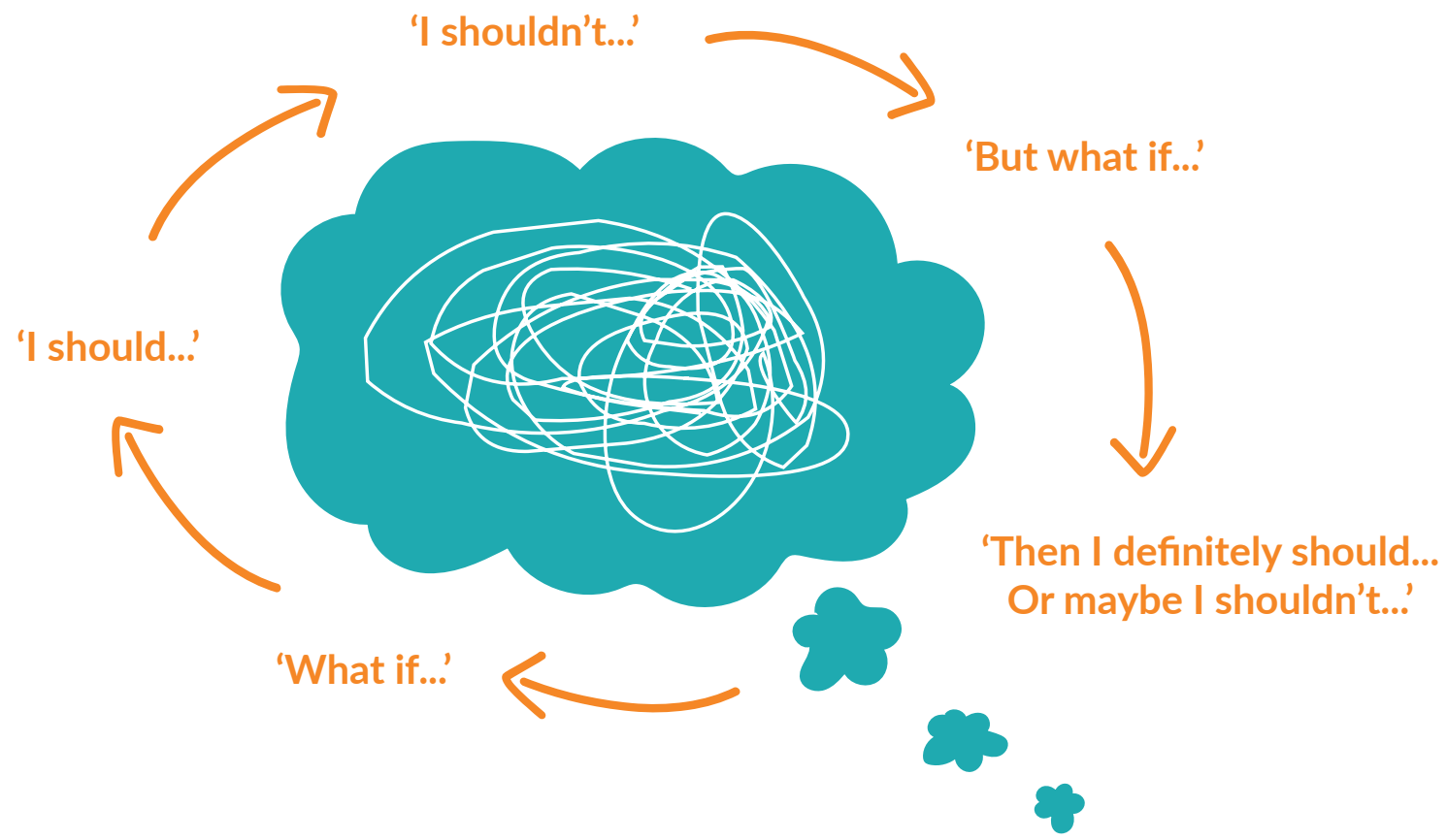

\section{Positive Beliefs About Worry}

One of the reasons people worry is because they think it's helpful.

For example:

- 'I need to worry about COVID-19, because I don't want to get ill'.

- 'I need to worry about my children, I don't want anything bad to happen them'.

- 'I need to worry about work because there is a recession and my job is under risk'.

Whilst these things are really important, the question is whether it is useful to worry about them or not. We certainly need to act on them: wash our hands, wear the mask and socially distance, but there is no advantage to worrying about them.

\section{Negative Beliefs About Worry}

On the opposite end, people also worry because they are worrying. For example:

- 'The stress of this will kill me'.

- 'I just don't want to think about it'.

- 'This stress is ruining everything'.

This type of worrying is a vicious circle.

- Worrying is a bad idea.

- Worrying about worrying is very bad idea. 
We do lots of things when we worry. Here are some typical examples. Do any of them seem familiar?

\section{Procrastination/Avoidance}

- Seek excessive amounts of information before making a decision (procrastination).

- Overlook positive or neutral information (focusing on the negative online).

- Put-off making a decision (procrastination).

- Over-analyse problems (excessive worrying).

- Fail to delegate and taking on everything yourself.

- Avoid thinking of the problem (avoidance).

- Become highly 'busy' (distraction/ avoidance).

- Take on different projects (distraction).

\section{Reassurance seeking}

What's the problem with reassurance seeking?

- The problem is it works. It makes us feel better... until we worry again.

- The more we seek reassurance, the less well it works.

\section{Checking}

Checking behaviours can also lead us to feel more worried/anxious as opposed to less. 'Google-itis' (using Google to check everything) is a particular issue in the age of COVID-19.

For example:

- We can check the news every couple of minutes.

- Then check the scientific, the epidemiological, the political responses.

- Continue checking the economic impact.

- Check the symptoms, the outcomes and personal stories.

All of this will increase our feeling of anxiety and depression, when our intention was to reduce On the following pages you will find eight steps which will help reduce anxiety.

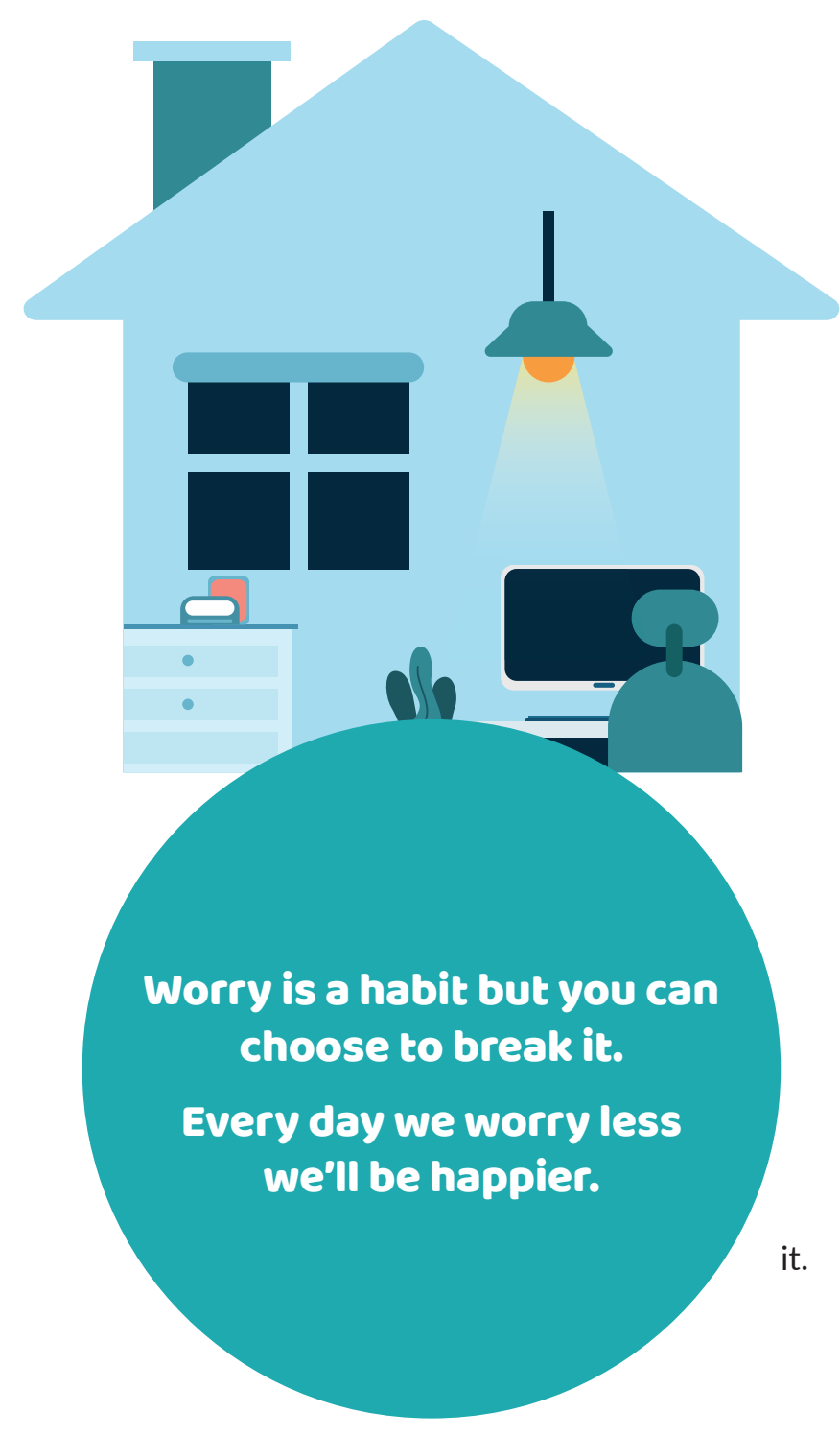




\section{Steps to Stop Worrying}

\section{Step 1: Commit to worrying less.}

- Most people readily agree to this step. They hate their worry. They would love to worry less

- But if you ask them to worry less about their children, their parents or their job, they struggle with that.

'But my children are important', 'My job is important'.

- We have to recognise that we worry about important stuff. Worry is just a useless response to important stuff.

\section{For example:}

NASA didn't land Apollo 13 by worrying about it. No one ever passed their Leaving Certificate, got driving lessons, went out on a date, got a promotion, bought a house or kept their family safe by simply worrying about it.

- Worrying is something internal, private and passive.

- Any situation in the real world needs something external, public and active.

That's what important issues need.

\section{Step 2: Measure the problem}

Take a diary and mark in with an asterisk $\left({ }^{*}\right)$ every time and place you worry and a guess about how long you worried for.

- Primarily, it makes you aware of a process that may have been automatic until now, when you marked all of those times. We need to notice how frequently we worry and most people will be a little shocked at what they see.

- Secondly, we need to pinpoint those occasions when we worry the most because these are the times we are going to target.

(Continued next page).

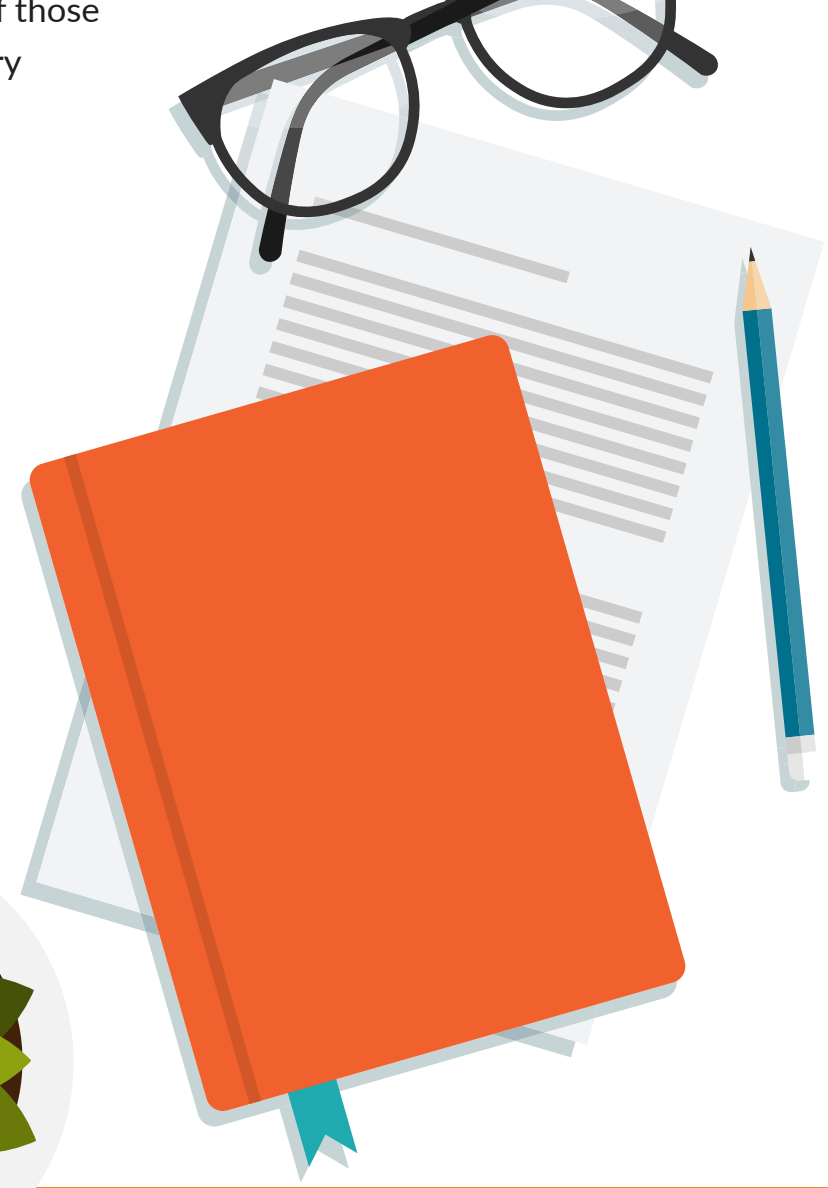


Decision-making is a core skill to combat worry.

A decision making tree

- It challenges procrastination.

- It challenges mental avoidance.

The next thing you need to do is pick up a pen and paper. If you try to problem-solve mentally, this can quickly spin off into worry.

- Write down the problem or the question.

- Now write down every solution you can think of.

- Now write down the first action you can take for each solution.

- Pick the best option.

- Do it.

- The key now is to take the action. Sometimes you will do all three options e.g. call the bank, ring your parents and look to sell, because they are immediate, medium-term and long-term solutions.

- In every situation, sometimes we cannot act. We can worry about a child but we cannot make them well. But we still have to take the steps we can and then work hard so our worry doesn't get in the way of making the next important decision

\section{Step 4: Starve worry of time and space.}

- Our long-term memory is amazing. We can remember tens of thousands of memories but our attention span is quite small.

- Often worriers will give themselves time and space to worry!

- If we want to reduce worry, we need to starve it of time and space. At key times, we need to add extra levels of stimulation and learn how to shift our attention from the internal to the external.

- We don't have to be busy 24/7 but when we want to relax that we actually engage in activities that are going to relax us (and not worry instead of relaxing).

- Don't drift into ourselves and stop engaging with the world around us (be present).

\section{Step 5: Flashlights and Polar Bears}

- When people worry they often ask how to stop thinking. Sadly, the human brain won't 'stop' thinking. It is like a flashlight, always pointed at something.

- With worry, we have to point the flashlight away from the worry and towards something else.

- For example: If I ask you to think of a pink polar bear, your brain is going to think of a pink polar bear - even if you don't want to.

- You must learn to point it at things that are external, specific and here and now, i.e. the real world!

- Often, people can confuse this with distraction. We are not trying to distract ourselves from the worry.

- We are trying to engage in the real, concrete world around us: people, places, activities and interests. 


\section{Step 6: Reducing checking/ reassurance-seeking}

- Checking and reassurance-seeking makes you feel better in the short-term but keeps the worry alive in the long-term.

- It means we are not engaged in our real life, we are too busy trying to check or seeking reassurance.

- It means we are becoming dependent on people or processes that will fail us (Google will not always give us the answer we want to hear).

\section{Step 7: Night Time}

Lots of worry happens at night time because it is when you have the fewest things to occupy your mind.

All the same rules apply:

- You have to choose not to focus on worry.

- You have to reduce the time spent on worry.

- You have to choose what you are going to focus your mind on.

- You may have to problem solve (for example: keep a notepad by the bed).

\section{Step 8: Challenge positive beliefs about worry}

How do I know I am doing the right thing?

- You have to make your best guess.

- This challenges lots of anxious beliefs that worriers have, for example:

'I should never make a mistake'.

'If I make a mistake, it will be catastrophic'.

'If I make a mistake, it will hurt the people I love'.

'It is better to be safe than sorry'.

\section{What do non-worriers believe?}

A second philosophy, of non-worriers:

- 'I'll do the best I can'.

- 'We'll muddle through'.

- 'I'll tackle each problem as it comes along'.

- 'I can only do what I can do'.

COVID has given us a lot to worry about. But if we can reduce the time we spend worrying, we'll feel happier and will be able to make better, safer decisions

\section{Practice Task}

Try putting the new philosophy into place.

Pick one of the eight steps and give it a go.

Test it for a week.

\section{Module Summary: Learning Points}

1. Worry has a role but worry without action just leaves us... worried.

2. We often worry because we believe it is helpful.

3. If we can spend less time worrying, we'll feel better and be better able to manage the challenges in our lives. 


\section{Module 4:}

Thoughts - The Impact of Negative Beliefs

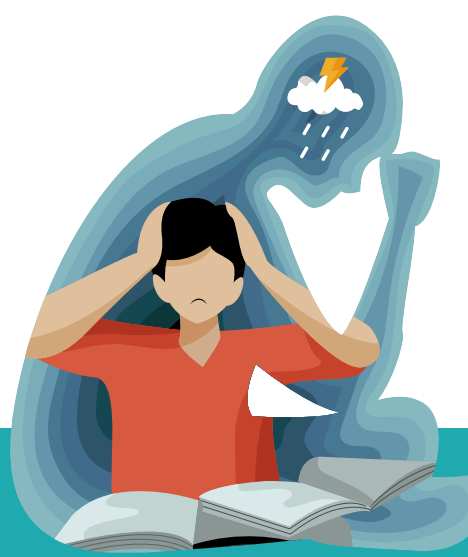

Our notions about happiness can prevent us from actually being happy.

We fail to see the opportunity for joy that is right in front of us when we are

caught in a belief that happiness should take a particular form" - Thich Nhat Hanh

\section{Module Aims:}

1. Examine how and why interpretations matter.

2. Gain better insight and understanding of our own beliefs around the COVID-19 crisis.

\section{Imagine this scenario:}

Four people are waiting at a bus stop. Three people are socially distanced, the fourth isn't.

- The first person in line begins to jump up and down waving her fists in the air and shouting - they're angry.

- The second person in line bursts into tears - they're distressed.

- The third person walks away rolling their eyes - they're amused.

The same thing has happened to all of them but they had three very different reactions.

\section{What was each of them thinking?}

A basic principle of CBT may help us understand the different reactions in this imagined scenario: a thought is not a fact. This means that the interpretation we make of a situation determines our emotional response.

Our interpretations are influenced by:

- Our previous experiences.

- Aspects of our personality.

- Our feelings about ourselves.

- Our relationships with others.

- Our world view.
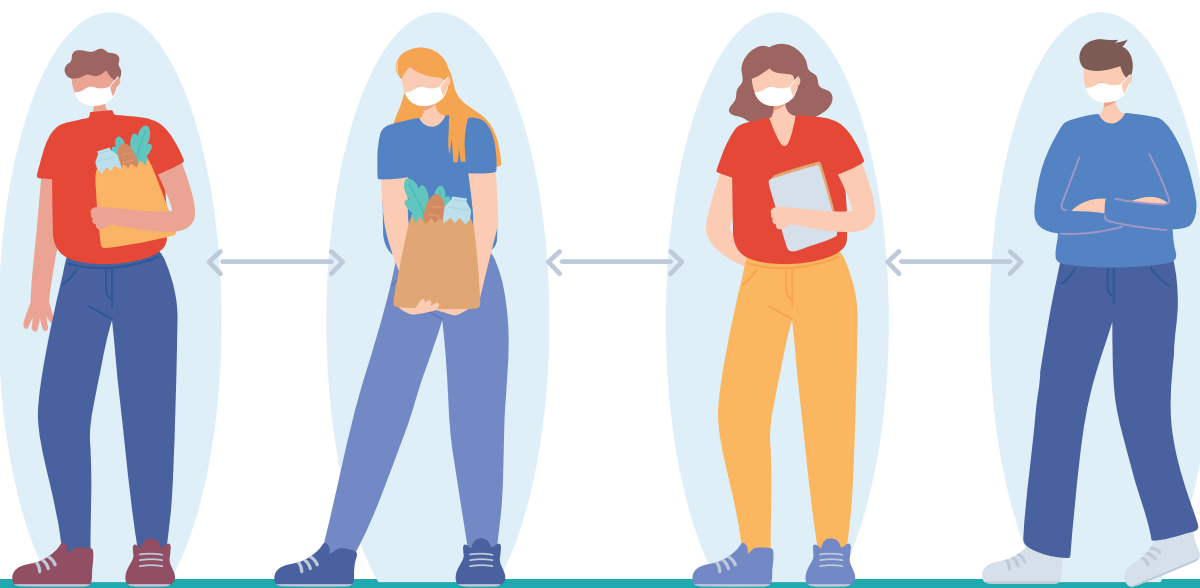


\section{How has your previous} experience influenced your reaction to COVID-19?

The way you think matters. Some events may be realistically dangerous, unpleasant or uncomfortable but we add to these by our thought processes, for example, by focusing on only negative aspects of a situation.

We have individual thinking styles and in certain situations these can be helpful or unhelpful. For instance, being very detailed-focused may be helpful in work but may mean we become overwhelmed when we have to deal with something out of our control like a pandemic.

Identifying unhelpful thoughts is the first step in understanding how we are thinking or what we are focusing on.

\section{Example:}

A grandparent who supports her daughter by minding her grandchildren may be really struggling. She needs to bring them with her to the supermarket to do the weekly shop. Other than this trip, the three of them are only leaving the house to go for walks and play in parks, but not in playgrounds. She does not want to take them with her to the supermarket, but recognises that they need food and she has no other option, but she is anxious about the risk this trip involves. When arriving at the supermarket, she sanitises their hands, and the supermarket trolley. The children are not allowed to hold on to the railing on the escalator and they are not allowed to touch any food goods unless they are wearing gloves. Each time she takes this trip, she comes back exhausted and incredibly anxious. She thinks if 'I get any more anxious than I won't be able to cope, or look after the children.'
Think about your own unhelpful anxious thoughts around the COVID-19 crisis. Then take a look at some of these typical responses or thoughts to the impact of COVID-19 crisis, which include:

- Fear of contamination and becoming ill (i.e. spreading the virus to those close to you).

- Negative experiences of social or economic situations.

- Experiences of trauma related to COVID-19 (i.e. someone close to you getting sick or dying).

- OCD-style responses (i.e. Obsessive compulsive disorders like checking).

Do any of these apply to you?

COVID-19 has thrown up a range of fears that we may never have had to face before:

- We may be afraid of becoming sick.

- We may afraid of making a loved one sick.

- We may be frightened because we are cut-off from the people we love and we feel alone.

- We may have constant decision making and so we are never settled on one response or action.

It is important to first recognise these fears and then next understand how they can be triggered, and finally, how they are affecting you. 
It can be beneficial to recognise that beliefs can vary. Take a look at some of these below and the associated thought process.

- Danger - 'I will be hurt'.

- Vulnerability - 'In certain situations, I'm weak/powerless'.

- Embarrassment - 'If I do something it will be humiliating'.

- Lack of control - 'I have to manage this'.

- Anxiety itself - 'If I get too anxious I will get overwhelmed/get ill etc.'

\section{Practice Task}

Write down your beliefs by finishing the following sentences:

\section{I am frightened that}

\section{I get down when I think}

\section{The world is}

The future is

My anxiety will

\section{Your Beliefs - Diary}

On the following page, we present a 'Negative Belief Diary'. The purpose of this is to examine what happens when you balance the evidence. Our beliefs often keep going because we only look at one side of the evidence, the side that confirms those beliefs.

We would encourage you to try it for at least a week.

\section{How to complete the 'Negative Belief Diary':}

In the 'Negative Belief' column - write the belief.

In the next column rate from 0-100\% how much you believe this belief (e.g. 89\%).

$\checkmark$ After that write the evidence 'For' - the evidence for why you believe this.

$\checkmark$ Then write the 'Evidence Against'- the evidence why this belief may not be true.

$\checkmark$ What is your 'Balanced Belief?' 
Diagram 10

Negative Belief Diary

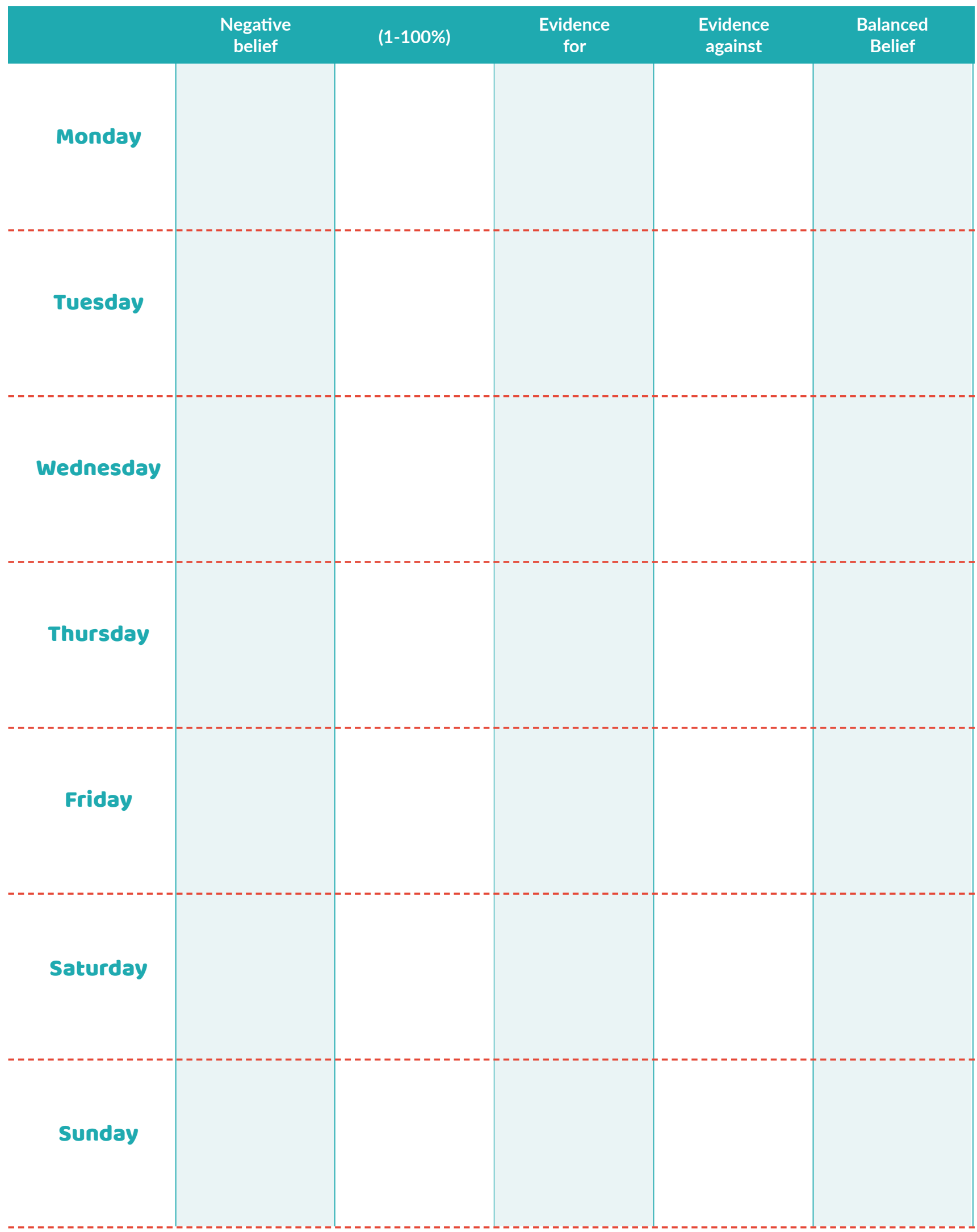




\section{Module Summary: Learning Points}

Use the space below to jot down some learning points from Module 4

\section{Practice Task}

Along with tracking your beliefs by using the 'Negative Belief Diary', start examining to see whether your beliefs are true or not.

Did you find any evidence that contradicted the belief?

Are your reactions always in-line with your balanced belief? 


\section{Notes}

Use this space for any extra notes or thoughts you have on your progress through the Workbook so far.
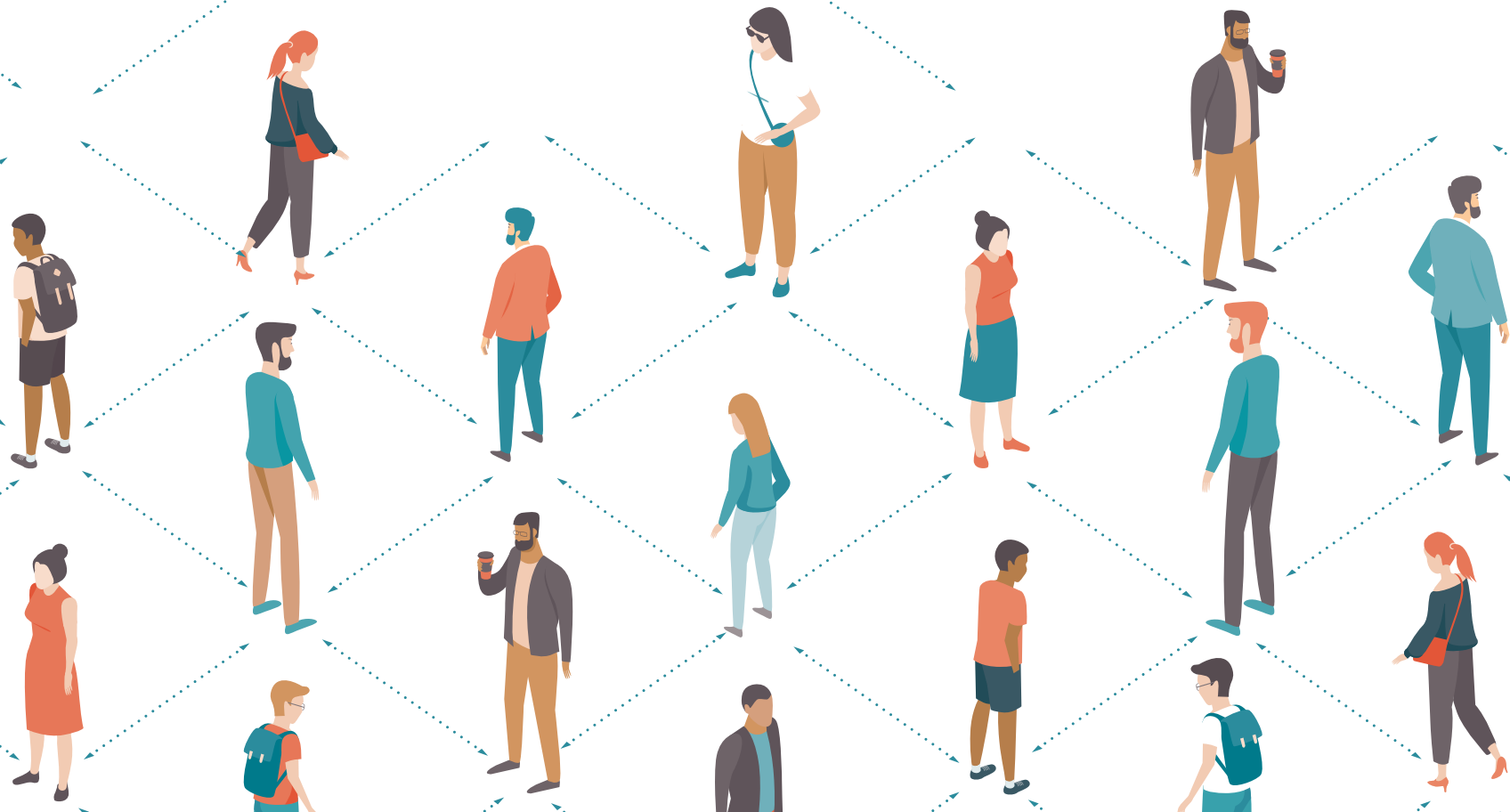


\section{Module 5:}

\section{Behavioural Experiments - Putting the Theory into Practice}

\section{Without fear there cannot be courage." - Christopher Paolini}

\section{Module Aims:}

1. Understand and implement the Theory A/B technique for analysing your beliefs.

2. Utilise the steps for planning a behavioural experiment and use this in real-world practice.

3. Examine your negative beliefs in light of this new experience.

\section{Theory A/B}

One technique for balancing risks is by using the 'Theory A/B'.

This involves three steps.

\section{Step 1: What's my Theory A/B?}

\section{Step 2: Testing out the belief}

\section{Step 3: Examining what does it mean about me, the world and the future?}

Consider the following steps and we can show you how to use this technique yourself.

Theory A: 'If I touch something, that someone else has touched, I'll contract COVID-19.'

Evidence for Theory A = A lot of people have COVID-19, maybe this person has COVID-19 also and by being in contact I will also.

Theory B: 'I am going to take reasonable precautions, but I can touch something, that someone else has touched and stay well.'

Evidence for Theory B = Not everyone has COVID-19. However, I can use hand sanitiser before I touch anything else or before and after touching the object that someone else has touched, just to be safe.

\section{Theory A/B - Try it out}

What is your Theory $A$ ?

Evidence for Theory A?
What is a potential Theory $\mathrm{B}$ ?

Evidence for Theory B? 


\section{Theory A/B Step 1: Example}

Acting safe or escaping from a dangerous situation is a sensible thing to do. It immediately reduces anxiety, but it has a drawback. It strengthens fear in the long run.

The more things we do to keep us safe from COVID-19, the more anxious we will become.

It was the right choice to have a lockdown, not go to parks, restaurants etc., in order to reduce the virus and 'flatten the curve'. However, as we start going back, we are going to be more anxious than we ever were before.

It is generally known that avoidance can grow and generalise.

Being afraid of touching something that someone else has touched, like a phone, can grow to not making calls. Fear of being in a crowded workplace can grow to become fear of being in the workplace at all, which could have serious consequences.

\section{Balancing Risks:}

In the age of COVID-19, we have to balance risks and try to make choices from our own best rationale rather than from our naturally anxious reaction.

\section{Theory A/B Step 2: Testing Out Negative Beliefs}

For Step 2 we use behavioural experiments. This is testing our evidence for or against our anxious beliefs. A behavioural experiment asks us to go and live like Theory B and see what happens; not rash, not unsafe but allowing our behaviour to follow our balanced thought.

'If I think it is reasonably safe to go back to work, I will try going back to work.'

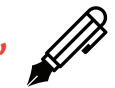

\section{Theory A/B: What should I do?}

\section{Theory A:}

\section{Evidence for Theory A:}

What I should do:

Theory B:

\section{Evidence for Theory B:}

What I should do: 


\section{Planning Your Behavioural Experiments}

Consider the following four steps for planning your behavioural experiments:

1. What is your anxious or negative thought? (Just pick one at a time to work on).

2. What is your balanced thought?

3. What does evidence for and against tell you?

4. What would happen if your balanced thought was true?

- How can I test this out in the real world?

- What can I observe?

-What has my prior experience taught me?

- What can I do?

- Is this realistic?

- Do I need support?

- How can I record the outcome so that I remember it?

- How am I going to treat myself afterwards?

\section{What would I do if my Theory B was true?}

1. Write down all of the things you would do if your Theory B was TRUE.

2. Make a list of the easiest and hardest things to do.

3. Start doing the easiest things (go at your own pace but challenge yourself) and try it for the next day or week.

4. Do I have any new evidence from my testing? (Use this to inform other Theory A/B beliefs) 


\section{Theory A/B Step 3:}

What does it mean about me, the world and the future?

Theory A:

Evidence for Theory A:

What I should do:

What does this mean for me?

What does it mean about me, other people, or the future? Perhaps it means I can cope better than I thought; or other people are a little kinder than I thought; or that the future is more hopeful than I thought.
Theory B:

Evidence for Theory B:

What I should do:

What does this mean for me? 


\section{Theory A/B}

When we arrive at new evidence from using the Theory A/B technique, it is seminal to test out your fears. We have provided a table that you can use to do this. In one side of the column it outlines what you need to fill in the other side. This will help display your predictions of your beliefs along with the results and how strongly you now hold that belief post-test

\section{Diagram 11}

New evidence: testing out my fears

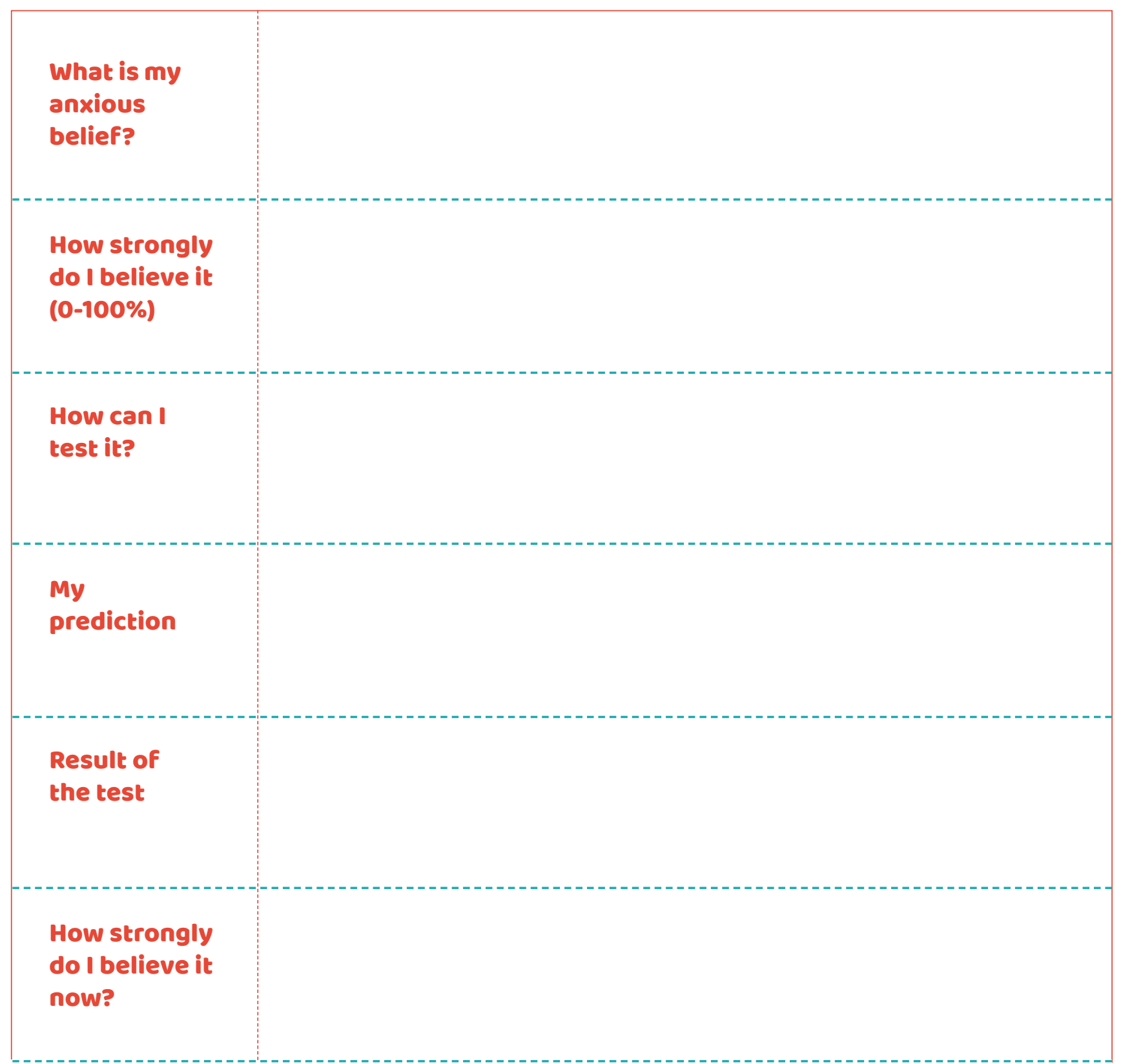




\section{Practice Task}

Before beginning the next module. Attempt to challenge at least two to three beliefs using the steps (1-3) of the Theory A/B technique. You can use or reuse the templates that we have provided

\section{Module Summary: Learning Points}

Use the space below to jot down some learning points from Module 5: Behavioural Experiments - Putting the Theory into Practice. 


\section{Module 6:}

Ever-Changing Demands

The universe doesn't allow perfection." - Stephen Hawking

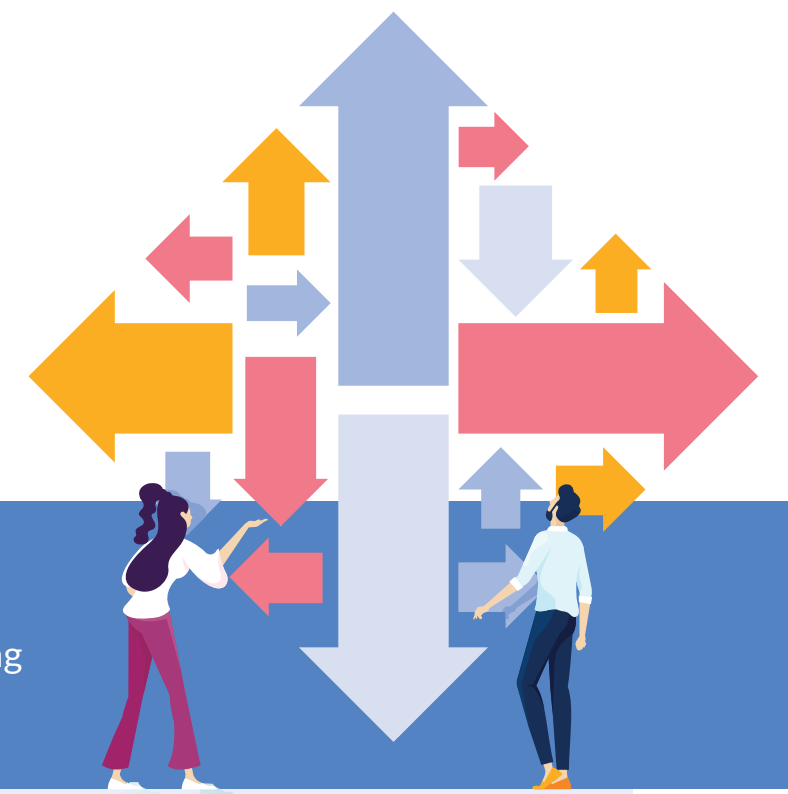

\section{Module Aims:}

1. Understand the difference between the 'old standards' and the 'new', how this affects decision making and the stress we experience in a time of COVID-19.

2. Implement strategies that allow you to 'Challenge the Inner Critic', along with adjusting rigid, inflexible or unrealistic standards that you may hold.

\section{COVID-19 Related Stress}

We all have standards and expectations for ourselves and the world. We might feel that it is important to work hard, or to be good parents, or to keep contact with our friends

Along with the old standards (before COVID), we now have to make many new decisions (due to changing Government guidelines) and face many new demands (e.g. home-working or lack of work, social distancing, isolation etc.). When these new demands and decisions clash with old standards it often leads to increased stress and potentially self-criticism.

Take a look at the diagram below - the diagram outlines how the ever-changing demands of COVID-19 can lead to increased stress and self-criticism.

\section{Diagram 12}

How decision making can lead to increased stress

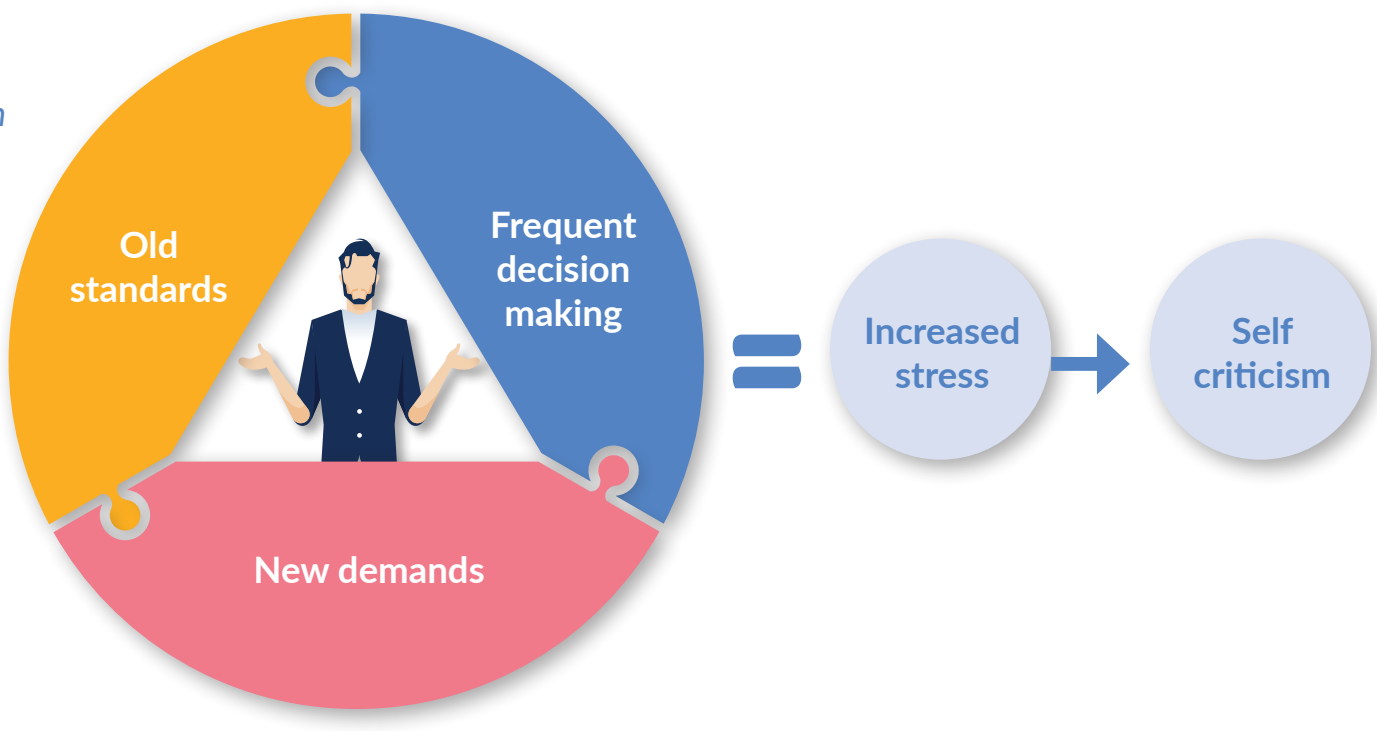


COVID-19 has demanded that we make repeated, rapid changes to our lives.

For example:

- Should we be in work/out of work/partially in work?

- Should our children be in school?

- Can I go to the shops?

- Can I visit my parents?

- Can I hug someone I love?

The answers to these questions were different throughout 2020. Changing guidelines can cause both confusion and uncertainty, especially if you want to try to do the right thing.

\section{Decision making}

\section{Decision making is deeply stressful.}

Think how long it takes to buy a pair of jeans or to change role in a job.

- As humans we make decisions slowly, weigh up the pros and cons, talk to people, ask opinions and play through scenarios in our minds. As such, rapidly making decisions makes us unsure and stressed.

\section{Decision making is tiring.}

- Think about how tired you are at the end of the day and someone asks you if you want tea or coffee? It can often be hard to make even a basic decision, let alone decisions around a crisis (e.g. Is it safe to go there? Who should I meet?).

\section{The more decisions we have to make the more stressed we get.}

- If we have to operate without our normal process of checking/talking etc., then we find this really stressful because we feel less able to weigh the pros and cons.

We experience a huge amount of stress now, having to make decisions about ordinary life events again and again.
Some typical advice around decision

making is:

- Build habits into your schedule.

- Make a choice and decide it's the right one.

- Keep decisions that bring you joy - cut what you can.

- Choose a role model.

- Use 'expert friends'.

None of these apply with the COVID-19 crisis:

- It implies that there is a right decision (when it may be unknown).

- That we can make a decision and stick to it (with changing information, we may not be able to stick to it).

- That we can spend a lot time thinking about it (in many circumstances, there is little time to think about it).

\section{Here are some tips for COVID-19 related decision making:}

1. It's ok. No one has a clue.

2. We don't really have control.

3. There is no one right decision.

4. You are going to feel stressed by having to make decisions. A lot. This is one of the biggest challenges with COVID-19.

5. Whatever decision you make now, you'll probably change later and that's ok.

6. Try to have some support in your decisions. It helps if friends and family think so too.

7. If someone thinks the opposite, that's ok too. 


\section{Challenging the Inner Critic}

COVID-19 has shifted how we work, how we socialise, our personal relationships, our friendships and our family life.

It is demanding that we are very, very different from how we used to be, but sometimes people (our family, our employer, our partners or ourselves) are expecting that we be the same as we always were. For example: we used to have an office - now we work in the back bedroom with a pullout desk, while the children bang on the door. But our workload hasn't decreased.

- Equally, other people have changed but not in the same way as us. Some people are meeting indoors, others outdoors. Some with face masks, some without.

- This creates an intolerable pressure for many people.

The inner critic is the part of us that nags away and is never satisfied with our performance - it is the voice that says 'you aren't good enough, working hard enough, clever enough, educated enough'. These new changes to our world often leaves us criticising ourselves for not being able to meet 'the standard'.

The inner critic is never satisfied and leaves us in a no win situation.

There are many reasons why we should challenge this 'inner critic' and combat self-criticism. Here are some examples:

- Self-criticism paralyses and makes you feel bad.

- Self-criticism is unfair.

- Self-criticism blocks learning.

- Self-criticism ignores reality.

- Self-criticism kicks you when you are down.

- Self-criticism is often the reason that we can't say something nice about ourselves. 'It doesn't feel right', 'It isn't true', or 'I don't deserve it'. 


\section{Change the 'tyranny of the shoulds'}

Often the inner critic comes in a series of 'Shoulds'. These are all the rules and standards that we hold ourselves to, often despite the reality of a situation.

These are also known as the 'tyranny of the shoulds':

'I should always...',

'I should never...'

Shoulds are:

$\checkmark$ Learned

Part of the culture that we grow up in

Linked to powerful emotion

Unreasonable

Rigid

COVID-19 doesn't respect any of these rules. It is making alterations to our lives and identities whether we like it or not. As such, it is important that to be able to change the rules that constrict us and limit our ability to grow.

\section{What are your shoulds?}

Complete the following using your own words:

- 'I should...'

- 'If I should never...'

- 'I should always...'

- 'Other people should always...'

Take a moment to think about what happens if you're not able to do this? Typically during the COVID pandemic there has been a range of things we would like to be able to do, that we 'should' do but haven't been able to. 


\section{COVID-19 doesn't know all}

the things you should do. I. It doesn't care. It won't l adapt, so we have to. $t^{6}$

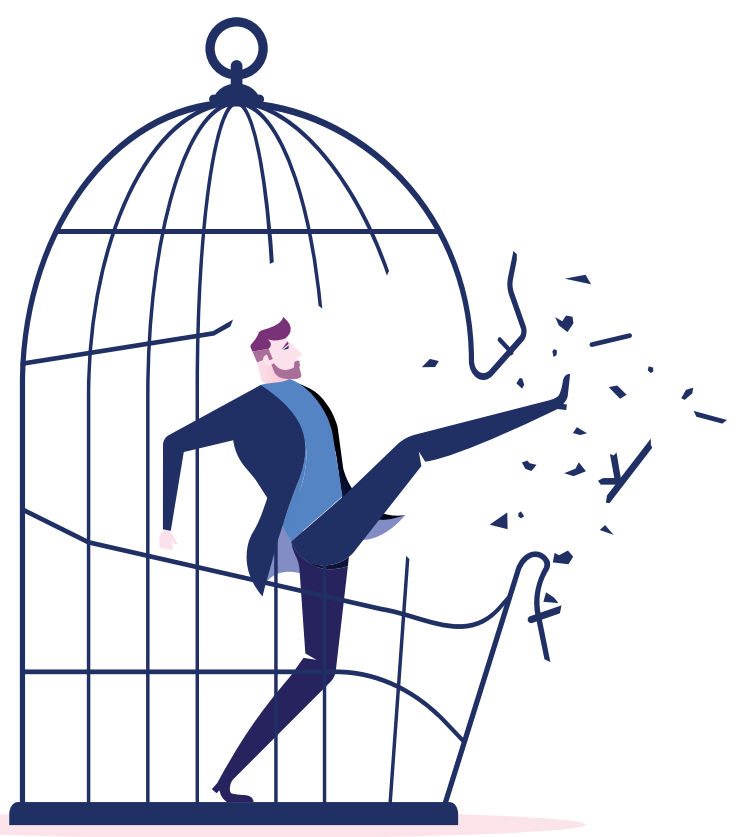

\section{Break the Rules!}

Answer the following, in relation to the shoulds you have just written down.

- Are they really true?

- Are they true all the time?

- Would you expect anyone else to follow these?

- What is stopping you from leaving them behind?

\section{Experiment with viewing yourself} more positively

There's another way to do it. Can we ask:

- Are my expectations possible in this situation?

- Are they reasonable?

- Am I able to meet my standards?

- What are new ways of working?

-What are new ways of achieving my goals?

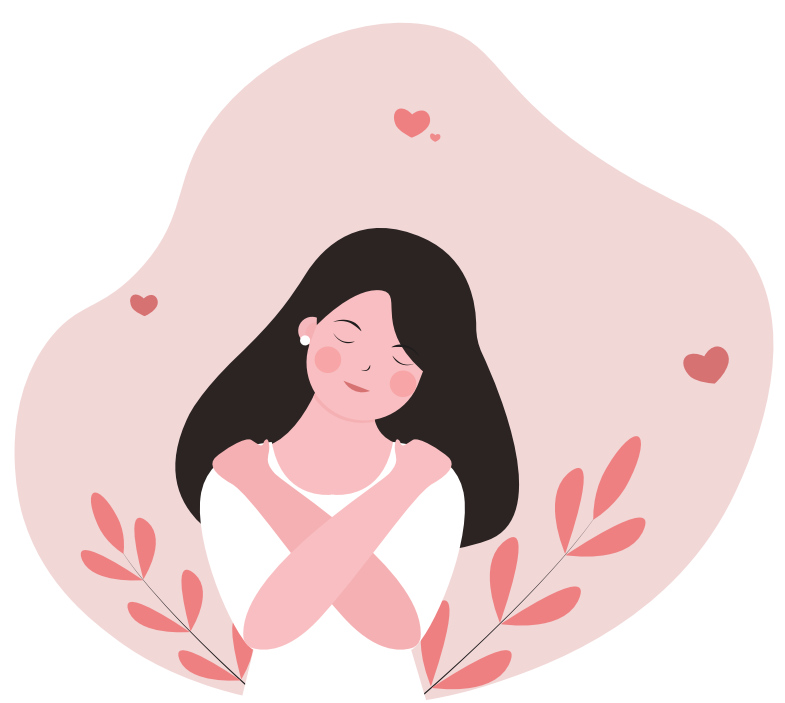




\section{Practice Task}

Write some new Coulds for yourself for the COVID-19 world. (I could go for a walk on Tuesday.)

I could

I could

I could

I could

I could

I could

I could

\section{Module Summary: Learning Points}

1. The pandemic doesn't respect our old rules and expectations.

2. Often others, or we ourselves, demand that we stay the same. This creates an intolerable pressure.

3. Can we gently adapt and create more flexible guidelines for ourselves?

\section{Key Message}

The world won't change so maybe your standards have to.

Can my standards be shifted to guidelines? This way it is less rigid and easier to follow. These guidelines can be something that I am happy if it happens, but it doesn't have to.

You can't criticise yourself for what you can't control.

Are there some things that I have to accept, even if I don't like them? 


\section{Module 7:}

Identity

Be yourself; everyone else is already taken." - Oscar Wilde

\section{Module Aims:}

1. To understand the importance of identity.

2. To understand the impact of losing some or all of your identity.

3. Develop steps and strategies to build confidence and self-acceptance

(positive self-statements, praise, self-compassion).

\section{Loss of Identity}

Our identity is the qualities, beliefs and personality that make us up. Our identity is made up of our many different roles: in our job, among our family, with our friends, through our interests and hobbies. The COVID-19 crisis has attacked many of the aspects that define us. I might be a brother, father, rugby fan, psychologist. But if I don't see my brother, can't watch rugby, can only conduct psychology through Zoom, am I still those things? A loss of identity is intrinsically anxiety provoking. We will often defend, hold onto or struggle to maintain our old sense of identity, even if it no longer makes sense. If a form of our identity is ripped away without anything replacing it, it causes a huge feeling of loss and sadness.

What does a loss of identity impact?

- My beliefs about myself.

- My day-to-day behaviour.

- My emotions.

- My body state.

- My performance at school, work or home.

- Personal relationships.

- My motivation for leisure activities.

- My self-care.

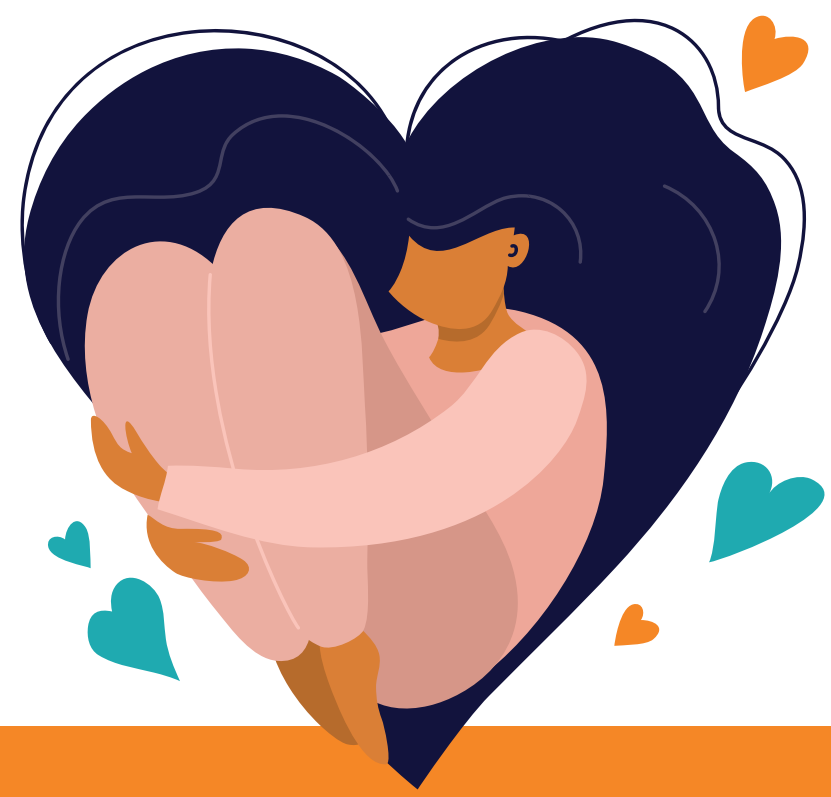




\section{Diagram 13}

Different aspects of identity

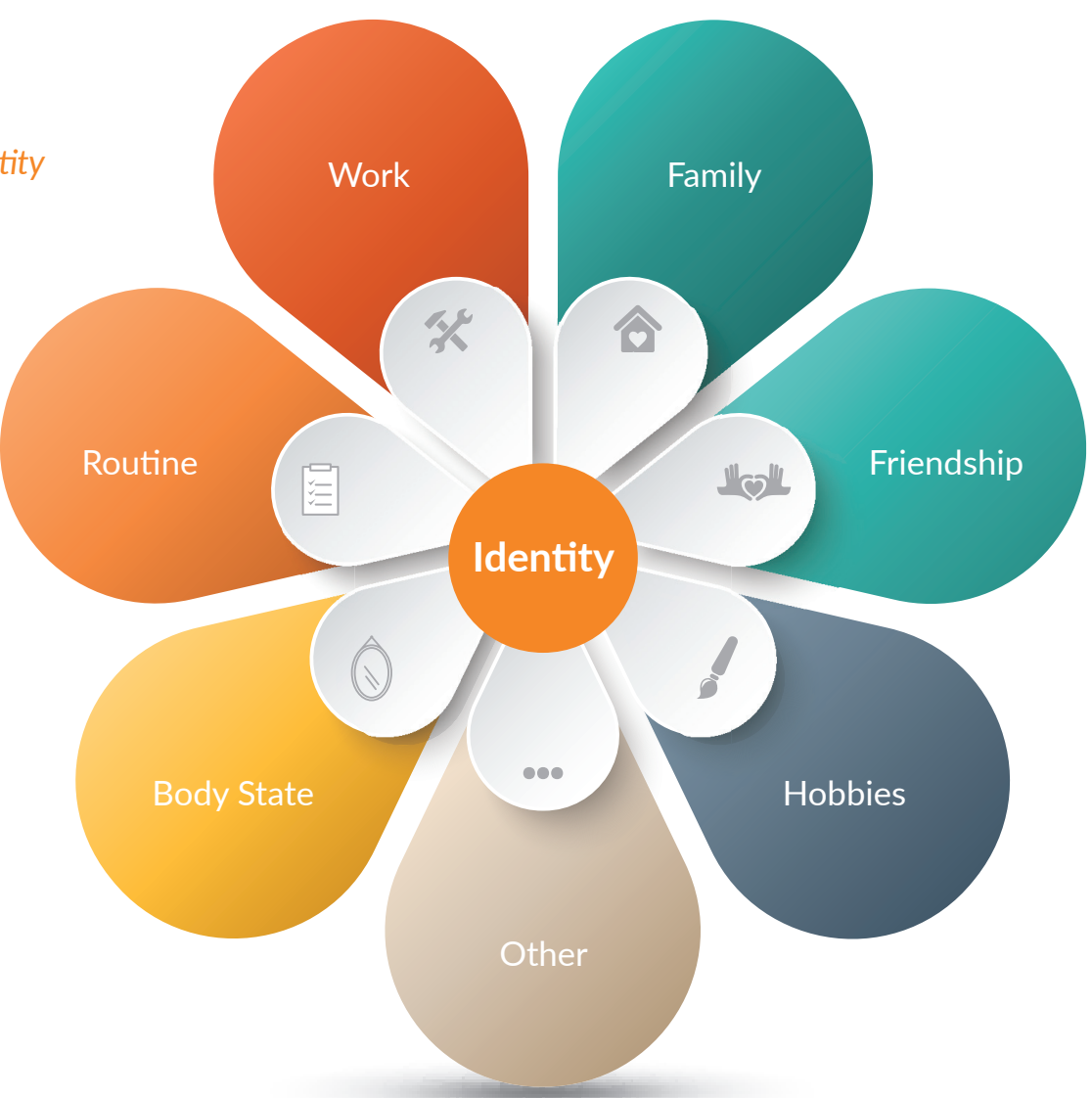

Has a loss of identity impacted you in any way?

Fill in any area where a loss of identity has impacted you.

My beliefs about myself:

My day-to-day behaviour:

My emotions:

My body state:

School or work:

Personal relationships:

Leisure activities:

Self-care: 


\section{New Identities}

COVID-19 is making a lot of demands of us. Often we can underestimate our ability to manage them. We make predictions of not coping, of not being able to take anything else on. We can fall into a sort of paralysis. COVID-19 has chipped away at so many things that we do but not who we are.

\section{Who else are you?}

Remember we are more than what we do. Even when everything else is stripped away, we are still made up of our passions and interests, personalities and histories. The first step is accepting who we are beyond the things that we do.

\section{You are more than what you do}

Sometime our self-acceptance is conditionally based on performance, achievement, external validation... but you are more than this. Accepting ourselves in theory seems quite easy, although it may take some work for you to get to that place. Self-acceptance is a way of thinking, feeling and acting that implies you accept, respect, trust and believe in yourself. Self-acceptance means you can live comfortably with your own strengths and weaknesses without lots of criticism. Self-acceptance also means you treat yourself the way you treat a friend - with care and support. Accepting yourself means you feel you deserve good things in life and are happy to fulfil your personal needs unconditionally.

\section{Diagram 14}

We are more than what we do. Sometimes our self-acceptance is conditionally based on performance, achievement, external validation...

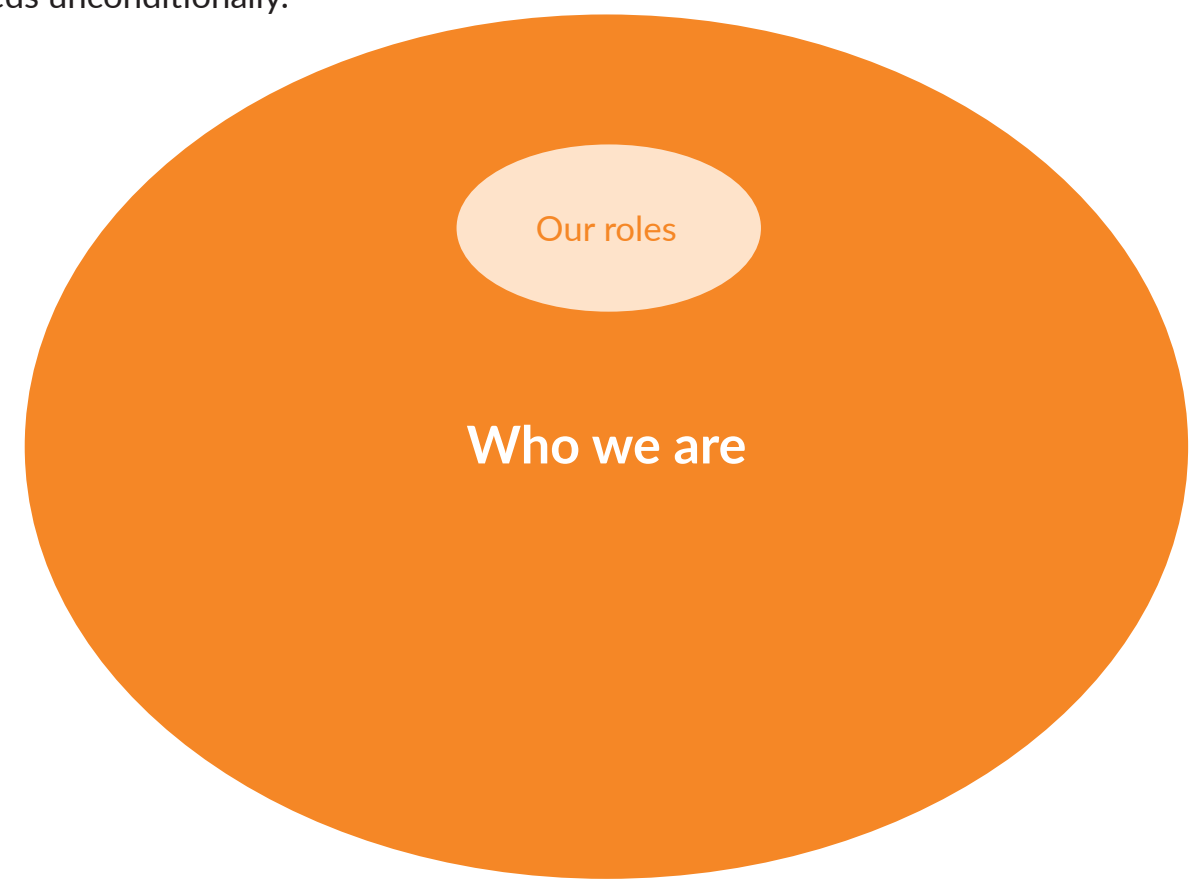

\section{Enhancing Self-Acceptance}

In order to enhance your level of self-acceptance, you must identify and recognise your strengths.

- Praise yourself - even for little achievements, every step is important. Praise every achievement, small or large.

- Learn to be your own best friend - you have to learn to give yourself support and encouragement.

- Be kind to yourself when you don't do as well as you'd have liked: how would you respond to someone else in that situation?

- Continue to congratulate and reward yourself for your effort as well as your successes (we may not always succeed, but trying is always the most important). 
What music

do I love?

\section{Diagram 15}

We are more than what we do.

What do these things tell me about myself?
What do I know about me that no one else knows?

\section{What is my} favourite memory?
What are some aspects of who I am?
What's my

favourite

TV show?

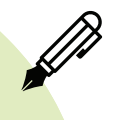

What really makes me laugh?

The voice in our head can be like two different coaches: one aggressive and critical and one reassuring and supportive. Which coach do you want to be to other people? Or to yourself? If you choose this coach now, is that how you always treated yourself?

\section{New Identities}

COVID-19 throws up logistical challenges but activities are still possible.

What can you do to build up your self-esteem? Here are some examples:

- Take on something new.

- Re-start something old.

- Push the boundaries a little.

- Enjoy yourself.

- Change the routine.

- Contact someone.

- Delete someone.

- Build yourself up.

Try some of these out before beginning the next module and see if they help build some self-esteem or confidence. 


\section{Building Positive Beliefs about Yourself}

Please write down five positive words to describe yourself.

1.

2.

3.

4.

5.

Now, please write down five balanced beliefs that you have about yourself by completing the sentences below (not entirely positive, not entirely negative e.g. 'I am great at getting work done, but only in the morning').

1. I am

2. I am

3. I am

4. I am

5. I am

Pulling all of this together means?

You are good enough.
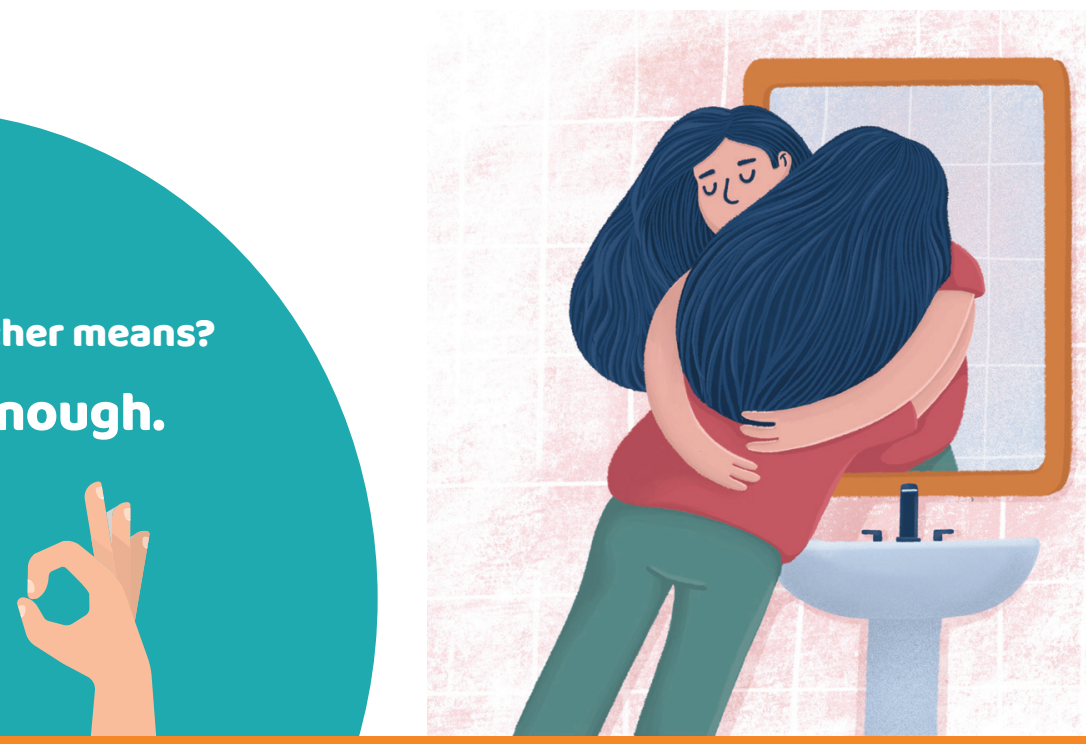


\section{Practice Task}

Answer the following questions.

What can you say about the situation (a situation in which you would normally self-critique) that allows you to accept it?

What can you say about yourself that allows you to accept yourself in the situation?

\section{Module Summary: Learning Points}

1. COVID-19 has taken away so much, it has been easy to lose a sense of who we are.

2. We are more than what we do.

3. We can remind ourselves who we really are and bring warmth and appreciation to that person. 


\section{Module 8:}

Review and Ending

There is no real ending It is just the place where you stop the story" - Frank Herbert

\section{Module Aims:}

1. As part of this review module, we would like to acknowledge some important concepts such as: practice, setbacks and failure.

3. Reflect on the progress you have made since Module 1.

\section{Keep the Practice Going:}

Some people find it difficult to keep practicing their new skills. This may be because:

- They don't think that they are making any progress, even though others see a change.

- Progress can be slow and may not always seem noticeable.

- They underrate their achievements: It is really important to praise yourself for your efforts. You are living through a pandemic and you are surviving. What you are doing is EXTRAORDINARY.

- You are facing all the fear in the world and coping. This is EXTRAORDINARY.

\section{Setbacks and Difficulties:}

- Setbacks are inevitable. They happen to everyone.

- When they occur people can sometimes become alarmed or lose motivation.

- A setback can be seen as devastating because the person has put a lot of effort into recovering.

- No matter how badly you feel during a setback, you have been building and building (don't let this setback destroy your amazing work).

- Setbacks often occur at times when you face additional stresses in your life, as well as trying to manage anxiety or low mood. Understand this and try to encourage self-acceptance and compassion. 


\section{Fail, Fail Again, Better:}

- Even if you slip back a little due to a setback, it isn't a catastrophe; you moved forward once, you can do it again.

- Ups and downs in anxiety and depression are the rule rather than the exception.

- Coping successfully with setbacks actually builds your confidence, and you are less likely to stumble over the same problem in the future.

- It is part and parcel of learning and growing.

- Being too afraid of failing, may stop you from achieving.

\section{What to do:}

Keep a record of what you are doing right. This can be used as evidence to yourself even if a setback occurs.

\section{Managing Setbacks:}

If you do experience a setback read through the hand-outs from this workbook again and follow these recommendations.

- Review your thought-challenging strategies and check for thinking errors.

- Be alert for 'Shoulds' and unhelpful expectations of yourself.

- Give yourself plenty of support and encouragement (this can be key and is often times the most forgotten about).

\section{Practice Task}

Allocate yourself some time to reflect on the progress you have made since you began Module 1 of this workbook 


\section{Winding Down and Closure}

The COVID-19 pandemic turned the world upside down and it turned many people's lives upside down. There is nothing surprising if you have felt anxious, stressed or low because of it.

The reality is that people have been managing incredibly, often while also managing feelings of depression or anxiety.

Congratulate yourself. What you are doing is amazing. You are living through history and surviving. None of this is easy. We hope that some of the exercises in this workbook resonate with you and work for you and that every day becomes a little more hopeful.

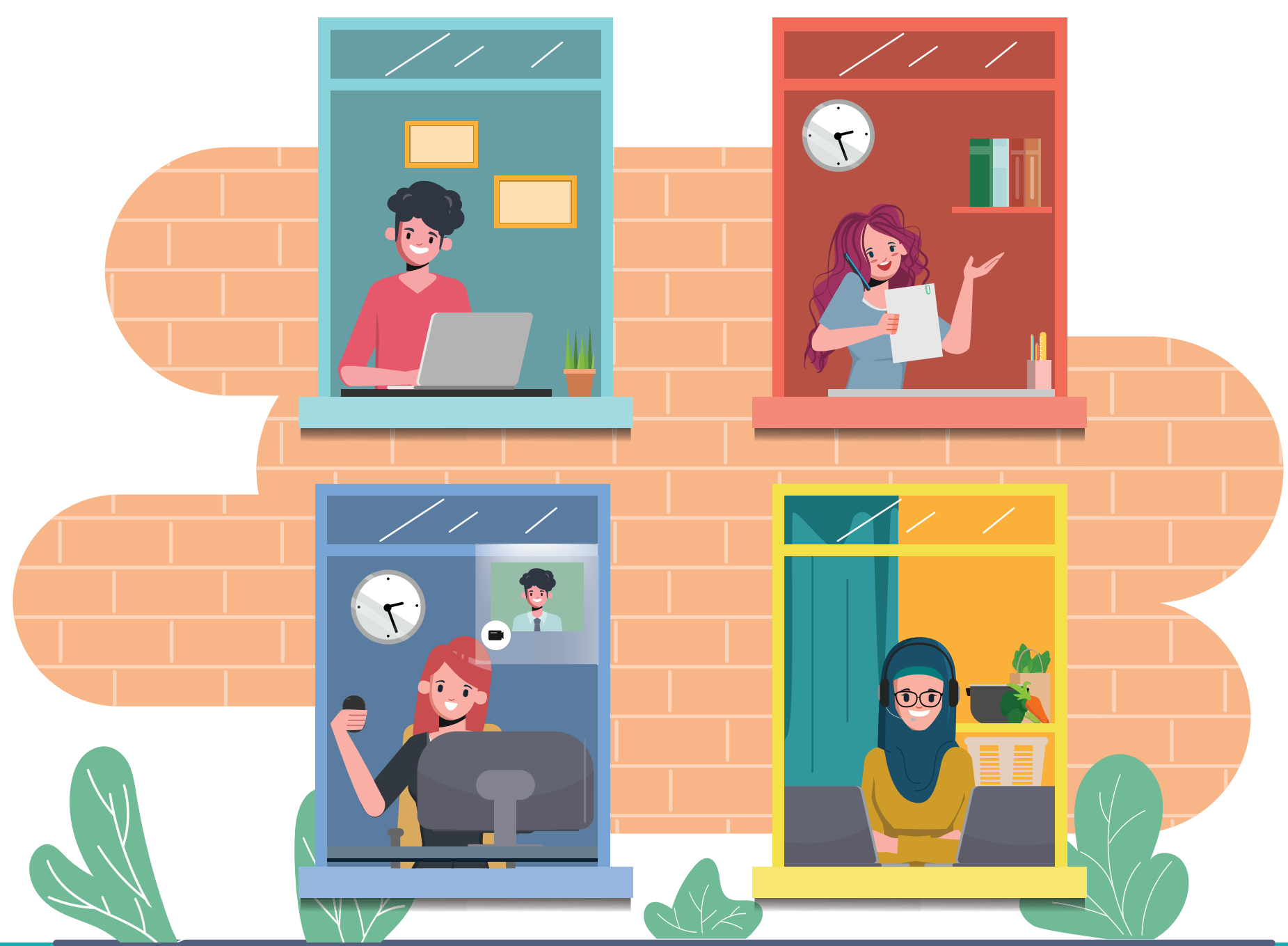


